\title{
ANNUAL AND SEASONAL MAPPING OF PEAK INTENSITY, MAGNITUDE AND DURATION OF EXTREME PRECIPITATION EVENTS ACROSS A CLIMATIC GRADIENT, NORTH-EAST SPAIN
}

Santiago Beguería $^{1 *}$, Sergio M. Vicente-Serrano ${ }^{* *}$, Juan I. López-Moreno $^{* *} \&$ José M. García-Ruiz $^{* *}$

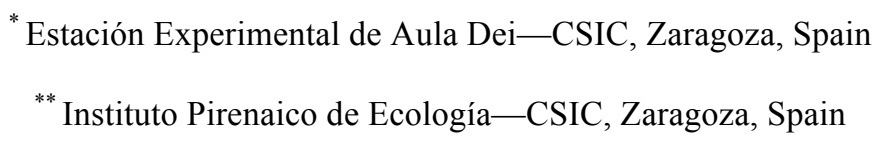

10 Abstract: Assessing the characteristics of extreme precipitation over large regions has a great interest, mainly due to its applications in hazard analysis. However, most of the analyses are reduced to daily

12 rainfall intensity, due to the fact that most long precipitation records were collected on a daily basis. Hazardous situations related to extreme precipitation events, however, can be originated either by very

14 intense rainfall, or by large accumulated precipitation due to the persistence of the rainy conditions over a long period of time. In this paper we show the use of a methodology based on the extreme value theory to

16 obtain continuous maps of quantiles of precipitation event parameters - peak intensity, magnitude and duration-for a large region with contrasted climatic characteristics in NE Iberian Peninsula. Spatial

18 models of the probability distributions parameters were calculated, which allowed constructing the regional probability models. The analysis was based on time series of precipitation events, which were 20 obtained from the original daily series. In addition to the usual annual-based analysis, seasonal analyses were also performed. This allowed the differences in the spatial distribution of the probability of extreme 22 events to be assessed at different times of year.

24 Keywords: extreme precipitation, daily precipitation, precipitation events, exponential distribution, regression-based interpolation, L-moments, peak intensity, magnitude, duration, Mediterranean, northeast

\section{Spain1. Introduction}

\footnotetext{
${ }^{1}$ Corresponding autor's E-mail: sbegueria@eead.csic.es
} 
The analysis of the characteristics of extreme precipitation events over large regions-especially of

28 probabilistic nature - has attained considerable attention, mainly due to its applications in hazard analysis.

Hazardous situations related to extreme precipitation events can be originated either by very intense

30 rainfall, or by large accumulated precipitation due to the persistence of rainy conditions over a long period of time. For example, dangerous phenomena such as torrential flooding are typically caused by

32 short, but very intense rainfall (White et al., 1997). On the other hand, regional floods are usually generated by long lasting rainfall, even if the intensity is not very high. Also, long sequences of

34 consecutive days with precipitation can favour the infiltration of water into the soil which may eventually cause their saturation and the triggering of landslides at a regional scale (Gallart and Clotet-Perarnau,

36 1988; García-Ruiz et al., 2002). Reliable estimations of the probability of extreme events are also required in land planning and management, the design of hydraulic structures, civil protection plans, and 38 other applications.

The extreme value theory provides a complete analysis of the statistical distribution of extreme 40 precipitation parameters, allowing for the construction of magnitude-frequency curves. Derived statistics such as quantile estimates - the average expected event for a given return period — have been widely used 42 to express the degree of hazard related to extreme precipitation at a given location. In most cases the analysis of extreme events has been reduced to the daily intensity (or whatever the sampling frequency of 44 the data), ignoring other important aspects such as the event's duration and its total magnitude. This is mainly a consequence of the structure of the data series, which are usually sampled at regular intervals, complicating the delimitation of rainfall events. However, an effort has to be made to shift from daily based to event based analysis, which will allow incorporating these parameters into the practice of 48 extreme precipitation analysis. Besides its greater information value, the event based approach has important methodological advantages over plain daily analysis, since daily precipitation series often 50 exhibit strong self-correlation, invalidating the independence assumption which is common to many methods. Aggregating the daily data series into series of events — often called 'declustering'—is usually a 52 pre-requisite in parametric frequency analysis, such as extreme events analysis (Beguería, 2005). 
The probability of occurrence of extreme events in terms of their intensity and duration changes between

54 regions and during the year, due to the different physical mechanisms that prevail at different seasons and the geographical features which affect them. This complexity makes traditional methodologies for assessing the probability of extreme precipitation events insufficiently flexible to address this problem in a complete manner. Standard methodologies based on the extreme value theory are generally restricted to 58 the fitting of the data from a single station to a probability distribution, usually known as 'at-site' analysis. However, this technique has been recently extended to regional analysis, in which the parameters of the 60 probability distributions are regionalised over the study area by means of one of several standard mapping techniques, from the simple division into homogeneous regions (Hosking and Wallis, 1993 and 1997) to

62 most advanced spatial regression techniques (Beguería and Vicente-Serrano, 2006; Casas et al., 2007). This allows making estimations of the probability of extreme events at ungauged locations, and to obtain

64 spatially continuous representations - maps - of the degree of hazard. Another important extension of the standard methodology refers to seasonal analysis, in addition to the more common annual analysis. By

66 dividing the original data series into seasonal event series it is possible to characterize the temporal variability of the process, allowing for a much more detailed analysis. In addition, seasonal hazard 68 analysis can be of great importance to several economic activities. For example, risk to agriculture of a given event can vary greatly during the year, as a function of the phenology of the cultivated species, and 70 the erosion risk can also be very different as a function of the state of the natural vegetation. In general, there is a lack of a commonly accepted methodology for regional extreme events analysis, so it can be 72 said that it is still a topic of methodological research.

Precipitation is a climatic element with a high spatial and temporal variability in the Iberian Peninsula 74 (Esteban-Parra et al., 1998; Muñoz-Díaz and Rodrigo, 2004; Vicente-Serrano, 2006). The reason is that the atmospheric processes which drive precipitation are quite complex (Rodríguez-Puebla et al., 1998 and 2001; Rodó et al., 1997; Martín-Vide and López-Bustins, 2006). In fact, neighbouring sectors can be affected by different weather types or atmospheric circulation patterns (Vicente-Serrano and LópezMoreno, 2006). Moreover, precipitation has a strong seasonality, determined by the latitudinal movement 
of the Polar front and the associated perturbations between the cold (northwards) and warm (southwards)

80 seasons. Therefore, the atmospheric circulation patterns change noticeably as a function of the season (Serrano et al., 1999; Martín-Vide and Fernández, 2001), which means that precipitation is generated by 82 completely different physical processes at different times of year (Llasat and Puigcerver, 1997). The relief of the Iberian Peninsula also introduces an important source of precipitation variability, which explains to 84 a larger extent the spatial variability of the average precipitation values (Egido et al., 1991; Ninyerola et al., 2000; Vicente-Serrano et al., 2003), and also of the most intense precipitation events (Llasat, 1990;

86 Llasat and Puigcerver, 1997; García-Ruiz et al., 2000; Peñarrocha et al., 2002; Beguería and VicenteSerrano, 2005).

88 Several papers have analysed the spatial and temporal variability of precipitation in the Iberian Peninsula. The majority of them are based on annual, monthly and seasonal data (e.g., Serrano et al., 1999; Esteban90 Parra et al., 1998; Muñoz-Díaz and Rodrigo, 2004). Nevertheless, other time-scales have also provided very interesting results such as pentad (five-day) precipitation (Andrés et al., 2005) or decad (ten-day) 92 precipitation (Caramelo and Manso, 2007). Thus, few days with precipitation of high intensity or magnitude can determine the dry or moist conditions of a given month, season or even a year. Moreover, 94 in wide regions of the Iberian Peninsula it is common that a high percentage of the annual precipitation is concentrated in a few rainy days (Martín-Vide, 2004). This leads to considerable uncertainty in the 96 pluviommetry of the region.

Some studies have focused on the analysis of temporal and spatial patterns of daily rainfall in the Iberian 98 Peninsula (e.g., Romero et al., 1999a; Lana et al., 2004; Martínez et al., 2007; Burgueño et al., 2005), the daily precipitation trends (González-Hidalgo et al., 2003; Gallego et al., 2006; Ramos and Martínez100 Casasnovas, 2006; Rodrigo and Trigo, 2007) and weather-type connections (Romero et al., 1999b). The analysis of extreme precipitation events has attained special attention (e.g. Puigcerver et al., 1986; Llasat 102 and Rodríguez, 1992; Llasat and Puigcerver, 1997; Peñarrocha et al., 2002), because in the Iberian Peninsula they cause highly negative impacts in the form of floods (Llasat et al., 2003; Llasat et al., 2005; 104 Barnolas and Llasat, 2007), landslides (Trigo et al., 2005) and soil erosion (Martínez-Casasnovas and 
Ramos, 2006; González-Hidalgo et al., 2007). As Rodrigo and Trigo (2007) highlighted: "the statistical 106 analysis of daily data in the Iberian Peninsula is very interesting from a climatic point of view, because monthly and annual values may conceal highly different precipitation regimes on the daily scale". From 108 an applied point of view, the analysis of daily precipitation has an unquestionable interest in many fields too, such as risk estimation, land management, infrastructure planning, civil defence, etc.

110 Most of the studies dedicated to the analysis of daily precipitation in the Iberian Peninsula focus on daily precipitation intensity. On the contrary, there are no examples of event based analysis. However, in most

112 of the area precipitation usually happens in events of more than one consecutive days. Due to this clustered nature of precipitation, the accumulated amount of rain recorded during precipitation events can

114 be very high, even if the peak daily intensity recorded is not large.

This paper analyses the annual and seasonal spatial patterns of extreme precipitation event parameters116 peak intensity, magnitude and duration - in a large area of northeast Spain with a strong AtlanticMediterranean climatic gradient. The purpose of the study is double: on one hand, to enrich the existent

118 knowledge about the spatial and temporal patterns of extreme precipitation in the Iberian Peninsula and, on the other hand, to develop and demonstrate the use of a methodology based on the extreme value 120 theory useful for regional precipitation related hazard analysis. In addition to standard annual analysis, a seasonal analysis has been performed due to the high seasonality of the climate in the region, considering

122 the applied aspects of the research since the hazard derived from extreme precipitation events can be very different throughout the year, and its assessment can be relevant for many economic sectors.

\section{Methodology}

\subsection{Study area}

The study area covers the northeast of Spain (Figure 1). The boundaries of the study area correspond to 128 administrative limits, including 18 provinces which cover an area of about $160,000 \mathrm{~km}^{2}$. The study area has strong relief contrasts. The main unit is the Ebro valley, an inner depression surrounded by high 130 mountain ranges. It is limited to the north by the Cantabrian Range and the Pyrenees, with maximum 
elevations above $3000 \mathrm{~m}$ a.s.l. The Iberian range closes the Ebro valley to the south, with maximum

132 elevations in the range of the $2000-2300 \mathrm{~m}$. To the west of the study area the main unit is the Meseta, a plain structure with elevations ranging between 700 and $900 \mathrm{~m}$ a.s.l. To the east, parallel to the

134 Mediterranean coast, the Catalan Coastal Range closes the Ebro valley, with maximum elevations between 1000 and $1200 \mathrm{~m}$ a.s.1.

\subsection{Data used}

138 A dense database with 459 complete daily precipitation series with continuous data between 1970 and 2002 was used in this study (see location of the observatories in Figure 1). The series were obtained by

140 means of a process that included reconstruction, gap filling, quality control and homogeneity testing (Beguería et al., 2007). Although the original database contained 828 data series, some of which had 142 more than 80 years of records, we selected the period between 1970 and 2002 for this analysis. A period of 32 years was considered enough for the extreme events methodology, which requires long datasets in

144 order to obtain reliable quantile estimates. For example, Porth et al. (2001) tried to determine the adequate sample size for return interval estimation and found that 20 years of data provided estimates 146 with a $20 \%$ rate of error, and in order to obtain the return periods with less than $20 \%$ error 25 or more years of data were necessary. In this case it was possible to lengthen the study period above 32 years, but

148 at the expense of having a significant reduction of the spatial density of the data, which was not desirable for a spatially explicit assessment.

150 A declustering process was applied to the original daily series to obtain series of rainfall events. A rainfall event was defined as a series of consecutive days with registered rainfall, so a period of one or more days

152 without precipitation was the criteria to separate between events. Declustering the series has important consequences for the analysis, since it usually eliminates the-undesired-serial dependence of the

154 process (Beguería, 2005). But it also allows for a more complete analysis compared to the raw daily series, since the duration and the total magnitude of the events can be analysed, too. Hence, three 156 parameters were determined for each precipitation event: its maximum intensity (in mm per day), total 
magnitude (accumulated precipitation, in $\mathrm{mm}$ ), and duration (in days). Each event was assigned to the last

158 date of the cluster, which allowed for constructing time series of precipitation events.

Apart from the complete series including all the events registered during the study period, four seasonal

160 event series were constructed, which included only the events that occurred during spring, summer, autumn and winter months. All further analyses were performed on these derived series.

\subsection{At-site extreme value analysis}

164 Classical at-site extreme value analysis consists on fitting a given probability distribution function to the highest values of a data series, in order to obtain reliable estimates of quantiles. 'At-site' refers here to the

166 fact that each data series is analysed separately, so if a set of series is analysed - for example, all the series belonging to a given region — the result is a set of individual probability models.

168 Several methods exist to sample the original data series for extracting the extreme observations. The methodology adopted in this study was based on exceedance, or peaks-over-threshold, sampling. Given

170 an original variable $X$, a derived exceedance variable $Y$ is constructed by taking only the exceedances over a pre-determined threshold value, $x_{0}$ :

$172 Y=X-x_{0}, \forall X>x_{0}$.

Exceedance series were obtained from the complete and seasonal event intensity, event magnitude and

174 event duration series.

A threshold value corresponding to the $90^{\text {th }}$ centile of each series was used to construct the exceedance

176 series. This means that only the ten percent highest events, in terms of intensity, magnitude and duration, were retained for the analysis. The selection of the threshold value is one of the most delicate tasks in extreme value analysis, since it is directly related to the assumption of independence of arrival times and exceedances. A low truncation value is desirable, since this increases the sample size and reduces the 180 uncertainties of the analysis. However, there is a risk of introducing serial dependence in the series if the events are too close in time, and thereby violating the independence assumption. In general, it has been 
182 shown that the declustering process reduces the problem of serial correlation to a large extent, allowing for threshold values as low as the $90^{\text {th }}$ centile (Beguería, 2005; Vicente-Serrano and Beguería, 2003).

184 As it has been demonstrated, the probability distribution of an exceedance or peaks over threshold variate with random occurrence times belongs to the Generalised Pareto (GP) family. The Poisson / GP model 186 has been used by numerous authors for extreme value analysis (i.e., van Montfort and Witter, 1986; Hosking and Wallis, 1987; Wang, 1991; Madsen and Rosbjerg, 1997; Martins and Stedinger, 2001). The 188 GP distribution is a flexible, long-tailed distribution described by a shape parameter $\kappa$, a scale parameter $\alpha$, and a location parameter $\xi$. It and has the following cumulative distribution function:

190 $\begin{array}{ll}P(X \leq x \mid \xi, \alpha, \kappa)=1-\left(1-\kappa \frac{x-\xi}{\alpha}\right)^{1 / \kappa}, & \kappa \neq 0 \\ P(X \leq x \mid \xi, \alpha, \kappa)=1-\exp \left(-\frac{x-\xi}{\alpha}\right), & \kappa=0\end{array}$.

The previous equation is expressed in terms of the original variate $X$, so the location parameter $\xi$ 192 corresponds to the threshold value used for obtaining the exccedance series. $\alpha$ can take any arbitrary value, and $\kappa$ controls the shape of the function — and hence the more or less pronounced character of its 194 right tail. For $\kappa>0$ the distribution is long-tailed-longest for smaller values of $\kappa$-and for $\kappa<0$ it becomes upper-bounded with the endpoint at $-\alpha / \kappa$. The GP distribution yields the Exponential 196 distribution as a special case when $\kappa=0$ (eq. 2, second expression).

Although the GP distribution is very flexible due to its three parameters, there is large uncertainty 198 involved in estimating the shape parameter $\kappa$ and it is frequently difficult to determine whether the estimates of $\kappa$ differ significantly from zero for a given sample. Uncertainty in the estimation of $\kappa$ 200 depends basically on the sample size, and there are tests designed to check the significance of the $\kappa$ estimations (Rosbjerg et al., 1992). On some occasions it is advisable to use the simplest Exponential 202 distribution instead of the GP, due its highest robustness. In the context of this study, the use of the Exponential distribution seemed very reasonable a priori, due to the significant reduction of the sample 204 size in the case of the seasonal series with respect to the complete — annual — datasets. Thus, the test by Rosbjerg et al. (1992) was used to check whether the null hypothesis that $\kappa=0$ could be rejected for a 
206 majority of the data series. It was found that the estimated values of $\kappa$ did not differ significantly from 0 for a large part of the seasonal series. Consequently, the Exponential distribution $(\kappa=0)$ was selected for 208 the analysis. Alternatively, L-moment plots where obtained as a graphical confirmation of the goodness of fit of the GP and the Exponential distribution to the data series. On these plots a comparison is made

210 between theoretical and empirical L-skewness $\left(\tau_{3}\right)$ and L-kurtosis $\left(\tau_{4}\right)$ - two distribution parameters which depend solely on the shape parameter $\kappa$-, which allows us to determine the appropriateness of a 212 given distribution function to model a given data set. Apart from the GP/Exponential model, lines corresponding to the Lognormal and Pearson III distributions have been also included as a way to 214 compare with other common heavily skewed distributions.

Under the Exponential distribution, and assuming Poisson distributed arrival times, the $T$-year return

216 period exceedance, $Y_{T}$, can be obtained as the $(1-1 / \lambda T)$ quantile in the distribution of the exceedances:

$X_{T}=x_{0}+\alpha \log \left(\frac{1}{\lambda T}\right)$

218 where $\lambda$ is the average frequency of the events in the exceedance series (expected number of events per year).

220 There are several ways to obtain sample estimates of the parameters of an Exponential distribution (see, i.e., Rao and Hamed, 2000). Here we have adopted the method of the probability weighted moments for 222 obtaining the at-site scale estimates, $\alpha$ (Hosking and Wallis, 1987). Although in exceedance series modelling there is no need to estimate the location parameter-it equals the threshold value-, we will

224 use the symbol $\xi$ for referring to at-site estimates of this parameter in the ongoing discussion.

\subsection{Regional extreme value analysis}

In many studies the use of the extreme value theory is reduced to at-site — independent — analysis. In the case of regional analyses, in order to obtain continuous maps of extreme value variates such as quantile or return periods, a common procedure is the subsequent mapping of at-site estimated quantiles by means of 230 interpolation techniques (e.g., Weisse and Bois, 2002; Prudhome and Reed, 1999; Casas et al., 2007). 
Opposing to this methodology, the goal of regional extreme value analysis is to obtain a single, common,

232 model of the probability of extreme events. Regional extreme value analysis relies on the idea that the parameters of the probability distributions of extreme events at close locations are similar, so

234 consequently this property could be used to obtain a general distribution by modelling this variability. This idea was first exploited in the analysis of river floods (Cunnane, 1988), and several alternative 236 methodologies have been proposed. One of the most broadly used methods is the index flood method (Stedinger and Lu, 1995; Madsen and Rosbjerg, 1997), in which a common shape parameter is obtained 238 by averaging the at-site estimations from the gauging stations on a given river or even in set of spatially close rivers. The subsequent probability distributions only differ in the scale parameter, which is 240 calculated individually for each gauging station. This method has the important advantage that the uncertainty in the estimation of the shape parameter is greatly reduced due to the concurrence of more 242 data on its calculation.

In the context of climatic variables, the regional method has been much less used, partly because the 244 relationship between parameters from different observatories is less evident. In the original methodology a common shape parameter needs to be found for a given region, so the problem of how to determine a 246 homogeneous region became crucial (Vogel and Fennessey, 1993; Hosking and Wallis, 1993). However, recent studies have shown that spatial interpolation techniques could be used to obtain smooth continuous 248 spatial representations of the probability distribution parameters, resulting in coherent and robust regional models and allowing for an easier spatial estimation of the extreme quantiles (Beguería and Vicente250 Serrano, 2006). Spatial interpolation techniques allow not only to use the information contained in the data series, but also to exploit the relationships existing between the modelled variable and other 252 geographic parameters such as the relief or the location with respect to the main climatic drivers. In this work we followed the same approach, extended to the case of a multivariate representation of extreme 254 precipitation events. 
A number of different interpolation procedures have been used to obtain maps from punctual 258 meteorological data, including global, local and geostatistical methods (Burrough and McDonnell, 1998). The most widely used procedures are global methods based on regression techniques, which relate the value of the target variable to a linear combination of spatially-explicit independent variables (Daly et al., 2002). This method allows exploiting the relationship existing between the target variable and other 262 variables which are known to control or influence its spatial distribution, and of which we can obtain or easily produce maps. Typical independent variables are those derived from digital terrain models, such as 264 the elevation, terrain shape, distance to the seas, etc. In contrast with regression methods, local and geostatistical methods exploit the spatial self-correlation existing in most spatial variables, such as

266 climatic parameters. This way, the value of a spatial parameter at a given point is estimated based on the value of the same parameter measured at close, known, locations. Since interpolated values at ungauged 268 locations depend on the observed values, local methods strongly depend on a sufficiently dense and evenly spaced sampling network. The methods of splines and kriging are among the most used local and 270 geostatistical methods.

During the last decade, several alternative forms of combined global and local models have been 272 proposed for interpolating spatially explicit environmental variables, such as different combinations of kriging and regression (Hudson and Wackernagel, 1994; Knotters et al., 1995; Goovaerts, 1999; 274 Ninyerola et al., 2000; Agnew and Palutikof, 2000; Bishop and McBratney, 2001; Brown and Comrie, 2002; McBratney et al, 2003; Beguería and Vicente-Serrano, 2006; Vicente-Serrano et al., 2007). These 276 and other studies have demonstrated that combined models usually allow for more precise and detailed representations of the target variables. In our case, parameter estimates at ungauged locations, $\pi\left(x_{0}\right)$, were

278 obtained as a mixture of a linear regression and a local autoregressive component:

$$
\hat{p}\left(x_{0}\right)=\sum_{i=0}^{n} \beta_{i} z_{i}(x)+\sum_{j=1}^{m} \lambda_{0} p_{j}+\varepsilon\left(x_{0}\right)
$$

280 or, in compact vector notation,

$\hat{p}\left(x_{0}\right)=\beta z(x)+\lambda(x) p(x)+\varepsilon(x)$, 
282 where $\hat{p}(\boldsymbol{x})$ represents a continuous field — a map —of the target parameter $p, \boldsymbol{z}(\boldsymbol{x})$ is a vector of spatiallyexplicit covariates, $\boldsymbol{\beta}$ is a vector of coefficients, which includes an intercept $\beta_{0}, \boldsymbol{p}(\boldsymbol{x})$ is a vector of known 284 values of $p$ at specific locations, $\lambda(\boldsymbol{x})$ is a weighting function field, and $\varepsilon(\boldsymbol{x})$ is a random error field. The first term in the right hand side of equation 5 represents the global trend component of the variance 286 of $p(\boldsymbol{x})$, and has the form of a linear regression. We used a set of independent variables at a spatial resolution of $1000 \mathrm{~m}$ as covariates (Table 1). Elevation is usually the main determinant of the spatial 288 distribution of climatic variables. Nevertheless, other variables such as latitude, longitude, distance to the oceans, slope gradient and aspect and incoming solar radiation may also have an important influence.

290 Most of variables were derived from a Digital Terrain Model at a resolution of $1 \mathrm{~km}$, except the distance to the Cantabrian and Mediterranean seas which were obtained from the Iberian Peninsula coastline 292 coverage, using the BUFFDIST module of the MiraMon GIS package (Pons, 2007). The latitude and longitude were obtained in UTM-30N coordinates using the same software. The slope aspect may be 294 important in the modelling of peak intensity, magnitude and duration parameters because it accounts for the effect of wind flows on precipitation events. The incoming solar radiation is a spatially continuous 296 variable that show the terrain aspect (northern and southern slopes have low and high incoming solar radiation values, respectively). Digital coverage of annual mean incoming solar radiation was created 298 using the MiraMon GIS and the DEM according to Pons (1996). Low-pass filters with radii of 5, 10 and $25 \mathrm{~km}$ were applied to elevation, slope and incoming solar radiation models in order to measure the wider 300 influence of these variables. Having such a large number of independent variables raises the problem of co-linearity - correlation between the independent variables-, which causes computational instability 302 and invalidates the results of regression analysis. To avoid this, a forward stepwise procedure with a restrictive 'probability to enter' $-\alpha=0.01-$ was used to select only the significant variables, as 304 recommended by Hair et al. (1998).

The second term in equation 5 represents the local variation of $p(\boldsymbol{x})$, and in this case the weights $\lambda(\boldsymbol{x})$ 306 have been obtained by means of splines with tension (Mitasova and Mitas, 1993), which has proved to be more suitable than other local techniques such as inverse-distance weighting or geostatistics (Ninyerola et 
308 al., 2007; Vicente-Serrano et al., 2003; Nalder and Wein, 1998). Since no GIS or statistical package known to the authors is able to fit the combined model in equation 5 in a single step, we first fitted the 310 regression and then fitted the splines to the residuals from the previous step.

As a result, a set of maps were obtained of the spatial estimates of the parameters of the Exponential

312 distribution, $\alpha(x)$ and $\hat{\xi}(x)$, and of the annual frequency of the events, $\hat{\lambda}(x)$, for the annual and seasonal series of event intensity, magnitude and duration.

\subsection{Validation}

316 Validating the fit of extreme distributions to the data is difficult, since the exact probability of the events is unknown. However, empirical cumulative probabilities can be assigned to the observed events via a

318 plotting position formula (Landwehr et al., 1979):

$$
C D F_{\text {emp }}(j) \equiv P\left(Y \leq y_{j}\right)=\frac{j+A}{n+B}
$$

320 where $y_{j}$ is the $j^{\text {th }}$ observation in the series of exceedances sorted in ascending order, and $n$ is the total number of observations in the series. The values of $A=0.15$ and $B=0$ were used, as recommended by

322 Landwehr et al. (1979) for similar long-tailed distributions. Quantile-quantile (QQ) plots were then obtained which relate the empirical probabilities and the ones obtained by means of the adjusted

324 Exponential distributions. QQ plots are a common technique for assessing if a dataset follows a given distribution function (see Chambers et al., 1983).

326 Additionally, a quantile plot-weighted correlation coefficient $\left(Q Q W R^{2}\right)$ statistic was computed as a measure of goodness-of-fit of the Exponential distributions to the data (based on Filliben, 1975): 
$Q Q W R^{2}=\frac{\left(\sum_{j=1}^{n}\left(y_{j} \hat{y}_{j}-\bar{y} \bar{y}\right) \omega_{j}\right)^{2}}{\sum_{j=1}^{n}\left(y_{j}^{2}-\bar{y}\right)^{2} \omega_{j} \sum_{j=1}^{n}\left(\hat{y}_{j}^{2}-\bar{y}\right)^{2} \omega_{j}}$

$328 \bar{y}=\frac{1}{\sum_{j=1}^{n} \omega_{j}} \sum_{j=1}^{n} y_{j} \omega_{j}$

$\bar{y}=\frac{1}{\sum_{j=1}^{n} \omega_{j}} \sum_{j=1}^{n} \hat{y}_{j} \omega_{j}$

where $\bar{y}$ and $\bar{y}$ are the weighted averages of the observed exceedances and the Exponential quantile 330 estimates, respectively. Because the number of small exceedances is much greater than the number of high exceedances, a weighting function $\omega(j)$ has been included; $\omega(j)$ is proportional to the probability of 332 exceedance, thus giving more importance to the highest, less-frequent observations in the sample, which are of greatest importance in extreme values analysis:

$334 \omega_{j}=\frac{1}{1-C D F_{e m p}(j)}$

To validate the EXP parameters maps, we randomly picked a $10 \%$ of the data series and reserved those 336 for subsequent tests (see location in figure 1). Several accuracy/error statistics were used (Willmott, 1982): Mean Bias Error $(M B E)$, which indicates the average over- or under- prediction; and Mean 338 Absolute Error $(M A E)$, which is a measure of the average error of the interpolation. We did not use the most widely used error statistic, the Root Mean Square Error (RMSE), because this statistic depends on

340 the variability in the squared errors, and hence it is impossible to discern the degree to which the $R M S E$ reflects the average error and to what extent it reflects variability in the distribution of squared errors

342 (Willmott and Matsuura, 2005). We also used the Willmott's $D$ agreement index (Willmott, 1981), a relative and bounded measure, to assess the map quality. The agreement index retains the average 344 information and does not amplify the importance of outliers. It also scales with the magnitude of the variables, which makes it possible to compare between variables independently of differences in their 346 magnitude and range. Table 2 provides the formulations of the accuracy statistics used in this study. 
These statistics were applied to the annual and seasonal maps of alpha and beta parameters for peak 348 intensity, magnitude and duration using the reserved dataset. Also the annual and seasonal maps of lambda values were validated.

350 Finally, accuracy statistics were also calculated for quantile estimates corresponding to a return period of 30 years using the at-site estimated parameters, $\{\hat{\alpha}, \hat{\xi}, \hat{\lambda}\}$, and the spatially modelled estimations, $352\{\hat{\alpha}(x), \xi(x), \hat{\lambda}(x)\}$

\section{3. Results and discussion}

\subsection{At-site analysis}

356 According to the methodological workflow described above, in a first stage Exponential distributions were fitted to the exceedance series. The appropriateness of the Generalized Pareto / Exponential 358 distribution was tested graphically by means of L-moment plots (figure 2). The closeness of the cloud of points - each point represents one observatory - to the theoretical line representing the GP model and its

360 simplified version in the form of the Exponential distribution supports the appropriateness of its use for this data set. The even spreading of the cloud of points along the GP line, especially for some of the 362 datasets, could be taken as evidence in favour of the GP distribution over the Exponential simplification. However, as it has been explained in the methods section, the reduction of the sample size in the seasonal 364 datasets did not allow the hypothesis of the GP distribution to be accepted for most of the observatories. In the case of the annual database, for which the sample size was approximately four times bigger, the use 366 of the GP distribution would have been a logical option. In other studies it has been shown that the GP distribution can be used and coherent spatial models can be fit to the parameter $\kappa$, for example by means 368 of a trend surface model (Beguería and Vicente-Serrano, 2006). For this study, however, we decided to maintain the use of the Exponential distribution for the annual database too for the sake of the 370 homogeneity and comparability of the results among datasets.

The best level of agreement with the GP/Exponential model was found for the annual dataset. The 372 seasonal datasets, as a consequence of the smallest sample size, showed less good agreement with the 
theoretical model. Between seasons, spring showed the best agreement, contrasting with the summer 374 datasets which showed the worst agreement. Between variables, both the peak intensity and the magnitude had a good agreement, contrasting with the event duration which exhibited the largest 376 dispersion among all datasets. The $Q Q W R^{2}$ statistics were very satisfactory, too (Table 3 ), and the comparison between datasets leads to identical conclusions to the L-moment plots. The lowest agreement

378 of the duration variable to the GP/Exponential model is probably related to the discrete nature of the variable, which is expressed in days. Further research on the best model for the event duration variable is 380 to be considered.

\section{3.2. Regional analysis: spatial parameter models}

In general, it was possible to obtain good regression models for all the parameters, both at the annual and

384 seasonal basis (Table 4 ). The $R^{2}$ values exceeded 0.60 in the majority of the cases, although there were differences as a function of the parameter modelled and the season. In general, annual parameters were better modelled than seasonal parameters, as it could be expected since the datasets had important differences in the sample size. No important differences were found between the goodness of fit of the models for $\hat{\alpha}(x)$ and $\xi(x)$, although the $R^{2}$ values were in general higher for peak intensity and duration than for magnitude. Differences in the model performance were quite noticeable between seasons, with 390 spring and summer exhibiting the lowest $R^{2}$ values, in general.

Regarding the variables included in the models, latitude was included in all the models as the first or the 392 second variable for $\hat{\lambda}(x)$. Also the distance to the sea or the distance to the Atlantic Ocean/Mediterranean Sea were often included. Between the topographic factors, the variables filtered using the greatest radius $394(25 \mathrm{~km})$ were usually included, indicating a very smoothed influence of relief on this parameter. The same was observed for $\hat{\alpha}(x)$ and $\xi(x)$. Despite the restrictive significance value used in the stepwise 396 procedure, a large number of variables entered the models in general, supporting the idea of a high spatial variability of the parameters. The distance to the sea and several topographic variables were the most important to model the parameters of peak intensity. For magnitude and duration, however, the variables 
related to the slope and the distance to the seas were usually the most important. Topographic variables 400 filtered using long radius (e.g., $25 \mathrm{~km}$.) had, in general, a greater importance and are more times included in the models than the variables filtered using short radius (e.g. $5 \mathrm{~km}$ ) or not filtered, showing again the 402 non local character of the influence of the relief on these parameters. An exception to this was the summer season, for which few variables were included in the models.

404 The spatial distribution of $\hat{\alpha}(x)$ and $\xi(x)$ on an annual basis showed important differences, and distinct patterns appeared (Figure 3).

406 For peak intensity, both $\hat{\alpha}(x)$ and $\xi(x)$ showed higher values close to the Mediterranean Sea and the Pyrenees, but also in some areas near the Atlantic coastland to the north. There is a transitional area in the 408 centre of the Ebro valley, and the lowest values for both parameters appeared in the western inner lands corresponding to the Meseta. In the north, close to the Atlantic Ocean, average values of $\hat{\alpha}(x)$ are 410 predominant, although $\xi(x)$ shows high values, similar to the ones observed in the Mediterranean coast land. In the Pyrenean Range there are some noticeable differences in the spatial distribution of $\hat{\alpha}(x)$ 412 and $\xi(x) . \xi(x)$ shows the highest values in the central Pyrenees, corresponding to the highest elevations, whereas $\alpha$ shows the highest values in the eastern part of the chain, close to the Mediterranean Sea.

414 The spatial patterns of $\hat{x}(x)$ and $\xi(x)$ for the annual magnitude show some similitude to the ones observed for peak intensity. High values of $\alpha$ are recorded in the Mediterranean coast land area and the Pyrenees, 416 but the highest values are recorded in the north of the study area, close to the Atlantic Ocean. Also low values are recorded to the east of the study area, but also in some regions in the centre of the Ebro valley 418 and the Iberian range. On the other hand, for $\xi(x)$ the spatial differences are more important, with a clear gradient throughout the study area. Lowest values of $\xi(x)$ appear in the centre of the Ebro valley, whereas

420 there is a progressive increase towards the north of the study area, where the highest values of $\xi(x)$ are shown.

422 Spatial patterns of $\hat{\alpha}(x)$ and $\xi(x)$ change in the case of the event duration. The highest values for both parameters are recorded in the northernmost area, corresponding to the Atlantic coast land, but as a 
424 difference to the trend observed for magnitude, low values of $\alpha$ appear in the Mediterranean coast land. Also some mountainous sectors of the Iberian range (westernmost chains) show high values of both 426 parameters. There is a spatial gradient from the northwest to the southeast. The lowest values of the parameters are found in the centre of the Ebro valley and along the Mediterranean coast land.

428 The spatial representation of $\hat{\alpha}(x)$ and $\xi(x)$ for peak intensity, magnitude and duration of events informs about the characteristics of the precipitation events in the region. They can be very intense but short in the 430 Mediterranean coast land and the Pyrenean range. On the contrary, in the Atlantic coast land, the events can have a very long duration but lower intensity, recording high accumulated magnitudes of rain. There 432 are spatial gradients between these two areas, with some spatial discontinuities caused by the relief. The magnitude parameters show a maximum to the north as a consequence of high precipitation amounts 434 recorded, despite the lower intensity of the events. Also high values of $\hat{\alpha}(x)$ are found in the Mediterranean coastland as a consequence of the short but intense events in this area. Therefore, high 436 values of $\hat{\alpha}(x)$ are found for event magnitude in both areas, which is caused by completely different characteristics of the events in terms of duration and intensity.

438 Regarding the validation of the spatial models of the Exponential distribution parameters (Figure 4 and Table 4), a good agreement was found in general between the regionalised parameters, $\{\hat{\alpha}(x), \xi(x), \hat{\lambda}(x)\}$, 440 and the ones obtained by at-site analysis, $\{\hat{\alpha}, \xi, \hat{\lambda}\}$. Nevertheless, some discrepancies were found between the regression lines and the line of perfect fit for the magnitude, for which the agreement between the 442 annual at-site and regionalised parameters was also lower than for peak intensity and duration $(D=0.75$ and $D=0.82$ for $\hat{\alpha}(x)$ and $\xi(x)$, respectively). This is due to local or random variance which was not 444 captured by the regression models, resulting in a spatial model that slightly underestimates the variability of the Exponential parameters for the magnitude. $D$ values for annual $\alpha(x)$ and $\xi(x)$ were higher than 0.94 446 both for peak intensity and duration. Nevertheless, independently of these few differences, the quality of the regional modes was very high, as the high values of the agreement index $(D)$ indicates. 
448 It would be impossible to analyse here the spatial patterns of each one of the parameters at seasonal basis here, so only the four seasonal maps for $\hat{\alpha}(x)$ are shown as an example (Figure 5). There are noticeable 450 seasonal differences in the spatial distribution of this parameter, with the highest values being recorded in the Mediterranean coastland and the eastern Pyrenees in autumn. In spring the spatial differences are 452 lower than in other seasons, although some high values are recorded in areas close to the Mediterranean Sea and the northernmost regions. In winter, the highest values of $\hat{\alpha}(x)$ are recorded in the eastern

\section{Pyrenees.}

Regarding the validation of the regional models at seasonal basis (Table 4), higher error statistics and a 456 lower performance was obtained for magnitude than for peak intensity and duration parameters, in agreement with the findings in the annual case. Nevertheless, in most of the cases the agreement index was very high, independently of the variable and parameter analysed, with the only exception of the summer magnitude parameters and the summer duration $\hat{\alpha}(x)$, which had $D$ values below 0.75 . These

460 results are clearly a consequence of the high uncertainty of precipitation during this season, due to the highly local convective processes responsible for most rain events. The creation of robust spatial models

462 for this season is difficult even when average precipitation values are analysed (Vicente-Serrano et al., 2007). It is normal that uncertainty increases when spatial patterns of extreme precipitation are analysed.

464 This highlights the need of applying local correction procedures such as the interpolation of residuals as it is applied in this research, since the inclusion of variables that record the local geographic and 466 topographic features at very detailed spatial scales (e.g., the incoming solar radiation and the slope) do not allow to obtain a noticeable improvement of the models.

\subsection{Annual maps of extreme quantiles}

470 Once the regional models of the Exponential distribution parameters have been validated and accepted, they can be used to obtain maps of peak intensity, magnitude and duration of the precipitation events

472 corresponding to a given return period. In the case of a return period of thirty years (Figure 5), the spatial patterns of quantile estimates for peak intensity, magnitude and duration are very different. Values higher 
474 than $140 \mathrm{~mm}$ in one day can be expected in the Mediterranean coastland, around the Ebro delta, the Barcelona coastland and the Catalan Pyrenees. In this last region the absolute maximum quantile 476 estimates for peak intensity can be expected (241 $\mathrm{mm}$ in one day). Values higher than $170 \mathrm{~mm}$ can also be expected in the Central Pyrenees, although in this case restricted to the areas with highest elevation.

478 There is a spatial gradient in the quantile estimates from the Mediterranean coastland to the western inlands, in which less than $60 \mathrm{~mm}$ is the maximum peak intensity expected in a period of 30 years. In the 480 northern Atlantic coastlands high peak intensity values $\left(>140 \mathrm{~mm}^{-d_{a y}{ }^{-1}}\right)$ can be expected in some areas, too.

482 Regarding the quantile estimates of the magnitude of precipitation events, the spatial differences are very important between the northern Atlantic coast land and the central Pyrenees, in which high magnitude 484 quantile estimates dominate, and the rest of the study area, with low quantile estimates. Thus, differences between the regions are relatively more important than those found for peak intensity and duration. The 486 highest magnitude estimates-650 $\mathrm{mm}$ in one single event - are predicted in the north of the Navarra region. On the contrary, a value of only $70 \mathrm{~mm}$ is predicted in the centre of the Ebro valley. In Catalonia 488 and the Mediterranean coast land values higher than $225 \mathrm{~mm}$ are common, with some local sectors that record with values higher than $325 \mathrm{~mm}$ near the Ebro delta and the eastern Pyrenees.

490 Finally, for event duration the quantile map shows the highest predicted values — above 20 days - in the Atlantic coast land and the Cantabrian Range. Also in the easternmost mountains of the Iberian Range are 492 expected event durations higher than 16 days. Average values between 12 and 18 days extend to the central Pyrenees, although the eastern Pyrenees show low duration estimates of less than 10 days. The 494 absolute lowest values are predicted recorded in the centre of the Ebro valley and along the Mediterranean coast land, with values maximum durations per event lower than 8 days.

496 The validation of the regionalised quantiles with respect to the at-site ones showed a very high level of agreement (Figure 7 and Table 5). For peak intensity and duration quantiles the agreement index $(D)$ is 498 0.96. For magnitude quantiles the $D$ value decreases to 0.85 . This value is also high and the performance of the regional models can be considered very good taking into account the high spatial variability of the 
500 variable. The $M A E$ for magnitude is $43.7 \mathrm{~mm}$, which is a low value in relative terms, regarding the high estimated values of this variable. The general pattern is towards a certain sub-estimation of the quantiles

502 by the regional model with respect to the at-site estimations, mainly for the series in which the highest values of event magnitude are estimated.

\subsection{Seasonal maps of extreme quantiles}

506 The spatial pattern of event peak intensity quantiles is highly contrasted between the different seasons (Figure 8). In Winter, high peak intensity values of more than $100 \mathrm{~mm}$ per day are predicted in large areas 508 of the north (Atlantic coast land and the Pyrenean Range), and the east (eastern Catalonia region). In the centre of the Ebro Valley and in the western inland areas maximum peak intensities lower than $40 \mathrm{~mm}$

510 per day are expected in winter. The spatial patterns of spring and summer are very similar, although in general the values of the expected peak intensity are lower than in winter. Autumn, on the contrary,

512 shows a very different spatial pattern, with the highest peak intensities predicted in the Mediterranean region and in the central and western Pyrenees. In some areas of the north-eastern Catalonia region peak

514 intensities higher than $300 \mathrm{~mm}$ per day are predicted.

The validation of the regionalised quantiles with respect to the at-site ones showed a very high level of

516 agreement for the four seasons (Table 5). The statistics show a good performance of the estimations, with very low mean absolute errors in relation to the range of the variable, and high $D$ values, which for

518 autumn and winter are above 0.95 . For summer the agreement between at-site and regionalised quantiles is lower than for other seasons, although the $D$ value is also very high $(D=0.88)$, which indicates a good

520 performance of the model.

With respect to the spatial pattern of event magnitude quantiles (Figure 9), noticeable seasonal

522 differences are also found, although some similarities can be observed for winter, spring and autumn. The highest event magnitudes are expected in winter, whilst the highest peak intensity occurs in autumn. The

524 centre of the Ebro valley shows the lowest magnitude quantile estimates in the four seasons. The highest seasonal contrasts are found in the Mediterranean coast land. In the northern Atlantic coastland high 
526 values are recorded in the different non-summer seasons, but in the Mediterranean coastland the highest values are recorded in autumn (more than $200 \mathrm{~mm}$ per event are expected in autumn in large areas).

528 Again, there is a good agreement between seasonal event magnitude quantiles estimated from regionalised and at-site estimated parameters (Table 5). For autumn and winter the relationship between 530 both estimates is very close, with an agreement index of $D=0.94$ and $D=0.93$, respectively. In spring, and summer the relationship is worse. In spring there is a general underestimation of the quantile 532 estimates using the regionalised parameters, and in summer the opposite behaviour is found.

In the case of the event duration quantiles (Figure 10), less differences are found in the seasonal spatial 534 patterns. The quantile estimates for winter, spring and autumn are very similar and resemble the pattern observed at an annual level. The highest event durations of events are predicted in the northern Atlantic 536 coast land and in the easternmost chains of the Iberian range. The predicted values of maximum duration are also similar between the three seasons: (more than 16 days in the north, and less than 8 days in the 538 Mediterranean coast land and the centre of the Ebro valley). The unique exception is the summer season, in which spatial patterns are more complex and a high spatial diversity in the quantile estimates is found,

540 in which the local factors seem to play an important role. The maximum duration of precipitation events recorded in summer for some areas can be the result of errors or anomalies in the models or the database.

542 Nevertheless, this behaviour is recorded specially in mountainous areas as in the Western Pyerenees. It is well known that the maximum precipitation amounts are recorded during the summer in this area 544 (Ninyerola et al., 2000), due to convective processes related to a high topographic diversity. Therefore, the results obtained in the north-east part of the study area agree with the expected climate of the region.

546 A non-expected pattern was obtained in the south-west, in which a bulls-eye effect can be observed around the observatory of Cubillejo de la Sierra, which could be due to very local residual errors in the 548 dataset.

With the exception of the summer there is a close relationship between regionalised and at-site estimated quantiles (Table 5). Mean absolute errors are lower than 1.32 days, and $D$ values are higher than 0.9 . In 
the summer, as a consequence of the higher local variability, a $D$ value of 0.70 is found, which implies a

552 higher uncertainty of the estimations.

To summarize the information about the extreme precipitation events a regionalization of the study area

554 was made as a function of the season in which the maximum quantile estimate for peak intensity, magnitude and duration is predicted (figure 11).

3.5. Spatial and seasonal patterns of extreme precipitation events in the NE Iberian Peninsula: meteorological interpretation

560 In general, the lowest event magnitude and duration have been found in the summer season, although high peak intensities are also expected, mainly in the inner regions. Generally, summer rains and showers

562 are caused by convective storms as a consequence of the frequent thermal lows that affect the Iberian Peninsula (Capel, 2000; Campins et al., 2000; Martín-Vide and Olcina, 2001). During this season, and 564 coinciding with dominant antyciclonic conditions and clear skies, there is a progressive warming of superficial air as a consequence of land warming. This causes a decrease of pressure in the superficial

566 atmospheric layer and an entrance of maritime air from the coastlands because the sea surface is colder as a consequence of thermal inertia. Thermal lows do not produce global precipitation in the region because 568 the moisture conditions are in general low, but they can produce intense and local precipitation as a consequence of the interaction between convective conditions and the relief. Therefore, the spatial 570 distribution of summer rains depends essentially on local factors, having a high spatial variability in time and space, which explains the lower quality of the parameter models and the quantile estimates for the 572 summer season compared to other seasons.

Higher duration and magnitude of precipitation events is found in autumn, spring and winter. During the 574 winter the atmospheric patterns that control precipitation in the Iberian Peninsula are the Atlantic perturbations associated to the Polar fronts that cross the Iberian Peninsula from west to east. These 576 perturbations cause precipitation events of relatively low intensity but of a spatially extensive nature and long duration. This explains the low peak intensities estimated in the majority of the study area in winter, 578 but also the highest magnitudes. 
Nevertheless, spatial variability is very high in the winter season, with the maximum magnitude values 580 expected in the Atlantic coastland and the western Pyrenees. In this case the relief also plays a major role because precipitation in the Atlantic coast is usually associated with northerly flows (Serrano et al., 582 1999). Under these conditions the Cantabrian chain, parallel to the coast, forces the air masses to ascend (orographic forcing), producing precipitation events of high magnitude and duration on the windward side 584 (northern slopes). On the contrary, the air mass reaches the southern slopes dry and hot because of the föhn effect. For this reason there is a very sharp and continuous spatial boundary between the northern 586 areas and the Ebro valley in winter, because this region is isolated with respect to the Atlantic influences by the Cantabrian chains.

588 The unique exception to this spatial pattern is the easternmost area of Catalonia, in which events of high magnitude are also expected in winter, but coinciding with high peak intensities of more than $140 \mathrm{~mm}$ per 590 day. Although the Polar front depressions are usually less strong when they arrive to the east, sometimes they are affected by a rapid cyclogenesis when they arrive at the Mediterranean Sea as a consequence of vorticity created by the asymmetrical heating pattern from the cold land to a relatively warm sea (Llasat and Puigcerver, 1997). This has the effect of reactivating the atmospheric instability, and the

594 Mediterranean Sea would provide the necessary moisture to cause intense precipitation events. Moreover, eastern Catalonia is also affected in winter by a precipitation pattern characterised by a centre of high 596 pressure over the Atlantic Ocean and a centre of low pressure over Algeria (Serrano et al., 1999). This situation causes an easterly wind flow of high moisture content as it crosses the Mediterranean, affecting 598 the easternmost areas of Catalonia which are open to these flows.

The westernmost sector of the study area (called 'La Meseta') does not show high estimated event peak 500 intensity and magnitude in winter and spring, but a high duration of events is expected (12 to 14 days). This sector has similarities to the precipitation variability in the eastern and central areas of the Iberian 502 Peninsula in autumn and winter (Serrano et al., 1999), the air masses arriving from the Atlantic ocean being the main source of precipitation since no mountain chains exist oriented in the northsouth direction 504 which act as topographical barriers. Therefore, strong westerly flows that drive the humid Atlantic air 
masses to the Peninsula would be the cause of major precipitation in the Meseta region. Nevertheless, 506 although the events can last for several days, the expected magnitude is low because the westerly flows that arrive to the study area are exhausted after crossing a major part of the Iberian Peninsula.

508 In autumn events of high magnitude and duration are expected over most of the study area, with the highest peak intensities expected along the Mediterranean coastland and in the eastern Pyrenees. Llasat 510 and Puigcerver (1997) identified two kind of extreme events affecting this region: i) short and high intensity summer or early autumn showers or thunderstorms, usually of local character; and ii), more 512 extensive events, usually during the autumn, which cause catastrophic floods. Both are caused mainly by convective activity and/or potential instability triggered by airflow and topographical features.

514 The high atmospheric instability that characterises the region during autumn and causes very intense precipitation are caused by the arrival of cold fronts generated by northerly, north-easterly or easterly 516 flows or cold continental air (cut-off lows) over the Mediterranean Sea (Ramis et al., 1997). The warm condition of this sea causes a moisture recharge of the air masses, which are subsequently transported 518 towards the coastland region in which the topography can favour torrential precipitation (Pastor et al., 2001). This explains the event peak intensities of more than $250 \mathrm{~mm}$ per day which are expected in this 520 area for a return period of 30 years. In fact, even higher values have been recorded a bit more to the south, in the Valencia region, where the absolute maximum reached $800 \mathrm{~mm}$ in 24 hours (Peñarrocha et al., 522 2002).

In general, the role of the relief is very important to explain the spatial distribution of the highest quantile 524 estimates, with a sharp boundary corresponding to the mountains that surround the Ebro valley in the centre of the study area. Air inflows in late summer and autumn caused by cut-off lows usually come 526 from the southeast. The coastal ranges which exist parallel to the coast line force the air masses to ascend, which causes its instabilization and explains the very high discharge in the chains near the littoral. If more 528 ascent is necessary for the instabilization of the air masses, then the highest precipitation rates are recorded in the mountains located further north (the Pyrenees), where the air flows are forced to ascend 530 even more (Llasat and Puigcerver, 1997). Thus, the highest concentration of cyclones in the whole 
western Mediterranean region is recorded to the south of the eastern Pyrenees (Campins et al., 2000). The

532 western slopes of the coastland ranges, however, are not affected by this phenomenon, and the highest peak intensities estimated for a period of 30 years are lower than $60 \mathrm{~mm}$, contrasting with values of more

534 than $160 \mathrm{~mm}$ expected in the eastern slopes.

Despite the high intensity, precipitation tends to be concentrated in a short number of days in the 536 Mediterranean coastal region (Martín-Vide, 2004). In fact, extreme precipitation events are usually concentrated within a few hours, and have also a marked spatial concentration because of the importance 538 of the local relief in the formation of convective systems (Peñarrocha et al., 2002). This also explains why the total event magnitude of the autumn events is smaller than in other regions in the study area, such as 540 the Atlantic coast.

An important role of the relief has been also observed in the case of the central Pyrenees, in which 542 southerly flows caused by low pressures in northwest Spain and the Gulf of Biscay are also the cause of important precipitation events in winter, spring and autumn (Romero et al., 1999b). The south-western

544 flows that affect the whole of the Iberian Peninsula and reach the Ebro Valley relatively exhausted are reactivated in the Pyrenees (Esteban et al. 2002; Vicente-Serrano 2005), which would help to explain the 546 high values of peak intensity and magnitude of events expected in this region during most of the year.

\section{Conclusions}

550 In this paper we have investigated the spatial distribution of the probability distribution parameters and quantile estimates of extreme precipitation event parameters - intensity, magnitude and duration-over a 552 large region in northeast Spain with a marked Atlantic-Mediterranean climatic transition. Apart from the global dataset including all the events, which we termed annual analysis, we performed independent 554 seasonal analysis considering only those events occurring in winter, spring, summer and autumn, in order to reflect the different physical mechanisms that originate rainfall at different times of year. 
556 The analysis has been based on precipitation events and not only on daily precipitation data, which allowed for a much more complete description of extreme precipitation in the region. Considering the 558 duration and total magnitude of the events, instead of only the daily intensity as it is usually done in many studies, is of great importance for practical reasons, for example in estimating the hazard associated to 560 extreme climatic events.

We have shown that the annual and seasonal exceedance series of event-related parameters can be fitted 562 with a high level of accuracy to the Exponential distribution, especially in the case of the events magnitude and intensity. In the case of the events duration the appropriateness of the Exponential 564 distribution was weaker at the seasonal scale, especially in the case of the summer events, proving that finding a single distribution representing the statistical behaviour of this variable for all series is a 566 difficult task that needs further study.

We choose the Exponential distribution in favour to its three-parameters and more flexible parent, the 568 Generalized Pareto distribution, because of its highest robustness due to having one less parameter. This decision was motivated by the reduction of the sample size when working at the seasonal level, and it was 570 ratified by an independent test. However, if the methodology outlined on this work is to be applied to other datasets, especially in the case of larger datasets — a dataset comprising 33 years was used here-, it

572 is advisable that the use of the GP distribution be considered.

Thanks to the high spatial density of the database it was possible to obtain a regional probability 574 distribution model based on multivariate regression and spatial interpolation techniques. This approach represents an improvement over previous approaches based on at-site estimates and subsequent 576 interpolation, because it increases the robustness of the models and helps in obtaining maps of quantile estimates for the required return periods, which is an important advantage for possible end-users. 578 Compared to other regionalisation methods based on delimiting homogeneous regions and using averaged parameters, the methodology used on this study allows for a much more detailed and accurate spatial representation. 
The method used on this study has demonstrated enough flexibility to capture the large heterogeneity of

582 precipitation present in the study region. Noticeable spatial and seasonal differences have been found for quantile estimates of peak intensity, magnitude and duration of the precipitation events, which can be explained by the atmospheric factors and processes that dominate the precipitation in the region. This demonstrates the usefulness of this methodology as a practical tool for regional hazard estimation applications, such as in planning preventive measures against regional torrential floods, or in land planning and management.

\section{Acknowledgements}

590 We would like to thank the National Institute of Meteorology (Spain) for providing the precipitation data base used in this study. This work has been supported by the following research projects: CGL2005-

04508/BOS (financed by the Spanish Commission of Science and Technology and FEDER), PIP176/2005 (financed by the Aragón Government), and "Programa de grupos de investigación consolidados" (BOA 48 of 20-04-2005), also financed by the Aragón Government. Research of S.B. is supported by a 'Ramón y Cajal' Research Grant from the Spanish Ministry of Science and Education.

\section{References}

Agnew MD, Palutikof JP. 2000. GIS-based construction of base line climatologies for the Mediterranean using terrain variables. Climate Research 14: 115-127.

Andrés M, Tomás C, DePablo F. 2000. Spatial patterns of the daily non-convective rainfall in Castilla y León (Spain). International Journal of Climatology 20: 1207-1224.

702 Barnolas M, Llasat MC. 2007. A flood geodatabase and its climatological applications: the case of Catalonia for the last century. Natural Hazards and Hearth Systems Science 7: 271-281.

Beguería S. 2005. Uncertainties in partial duration series modelling of extremes related to the choice of the threshold value. Journal of Hydrology 303: 215-230.

Begueria S, Vicente Serrano SM. 2006. Mapping the hazard of extreme rainfall by peaks-over-threshold extreme value analysis and spatial regression techniques. Journal of Applied Meteorology and Climatology 45: 108-124.

Beguería S, Vicente-Serrano SM, López-Moreno JI, García-Vera MA, Stepanek P. 2007. A complete daily precipitation database for north-east Spain: reconstruction, quality control and homogeneity. Submitted to International Journal of Climatology.

712 Bishop T, McBratney A. 2001. A comparison of prediction methods for the creation of field-extent soil property maps. Geoderma 103: 149-160.

714 Brown DP, Comrie AC. 2002. Spatial modeling of winter temperature and precipitation in Arizona and New Mexico, USA. Climate Research 22: 115-128. 
716 Burgueño A, Martínez MD, Lana X, Serra C. 2005. Statistical distributions of the daily rainfall regime in Catalonia (northeastern Spain) for the years 1950-2000. International Journal of Climatology 25: 1381-1403.

Burrough PA, McDonnell RA. 1998. Principles of Geographical Information Systems. Oxford University Press: Oxford.

Casas MC, Herrero M, Ninyerola M, Pons X, Rodríguez R, Rius A, Redaño A. 2007. Analysis and objective mapping of extreme daily rainfall in Catalonia. International Journal of Climatology 27: 399-409

Campins J, Genovés A, Jansá A, Guijarro JA, Ramis C. 2000. A catalogue and classification of surface yclones for the western mediterranean. International Journal of Climatology 20: 969-984.

Capel JJ. 2000. El clima de la Península Ibérica. Ariel. Barcelona.

Caramelo L, Manso MD. 2007. A study of precipitation variability in the Duero basin (Iberian Peninsula). International Journal of Climatology 27: 327-339.

Chambers J, Cleveland W, Kleiner B, Tukey P. 1983. Graphical Methods for Data Analysis. Wadsworth, $239 \mathrm{pp}$.

Creus J, Ferraz J. 1995. Irregularidad pluviométrica y continentalidad térmica en el valle medio del Ebro. Lucas Mallada 7: 147-164.

Cunnane C. 1988. Methods and merits of regional flood frequency analysis. Journal of Hydrology 100: 269-290.

Daly C, Gibson WP, Taylor GH, Johnson GL, Pasteris P. 2002. A knowledge-based approach to the statistical mapping of climate. Climate Research 22: 99-113.

Egido A, Egido M, Seco J, Garmendia J. 1991. Quantitative relationships of mean seasonal precipitation in the Tagus river basin (Spain). International Journal of Climatology 11: 1-18.

Esteban P, Soler X, Prohom M, Planchon O. 2002. La distribución de la precipitación a través del índice NAO. El efecto del relieve a escala local: El Pirineo Oriental. El Agua y el Clima, J. A. Guijarro et al., Eds., Asociación Española de Climatología, 25-34.

Esteban-Parra MJ, Rodrigo FS, Castro-Díez Y. 1998. Spatial and temporal patterns of precipitation in Spain for the period 1880-1992. International Journal of Climatology 18: 1557-1574.

Filliben JJ. 1975. The probability plot correlation coefficient test for normality. Technometrics 17: 111117.

Gallart F, Clotet-Perarnau N. 1988. Some aspects of the geomorphic processes triggered by an extreme rainfall event: the November 1982 flood in the Eastern Pyrenees. Catena Suppl. 13: 79-95.

Gallego MC, Garcia JA, Vaquero JM, Mateos VL. 2006. Changes in frequency and intensity of daily precipitation over the Iberian Peninsula. Journal of Geophysical Research-Atmospheres 111: D24105.

García-Ruiz JM, Arnáez J, White SM, Lorente A, Beguería S. 2000. Uncertainty assessment in the prediction of extreme rainfall events: An example from the central Spanish Pyrenees. Hydrological Processes 14, 887-898.

García-Ruiz JM, Martí-Bono C, Lorente A, Beguería S. 2002. Geomorphological consequences of frequent and infrequent pluviometric and hydrological events in a Mediterranean mountain area. Mitigation and adaptation strategies for global change 7: 303-320.

Garrido J, García JA. 1992. Periodic signals in Spanish monthly precipitation data. Theoretical and Applied Climatology 45: 97-106.

González-Hidalgo JC, De Luis M, Raventos J, Sánchez R. 2003. Daily rainfall trend in the Valencia Region of Spain. Theoretical and Applied Climatology 75: 117-130.

González-Hidalgo JC, Peña JL, de Luis M. 2007. A review of daily soil erosion in Western Mediterranean areas. Catena doi:10.1016/j.catena.2007.03.005

Goovaerts P. 1999. Using elevation to aid the geostatistical mapping of rainfall erosivity. Catena 34: 227-242.

Hair JF, Anderson RE, Tatham RL, Black WC. 1998. Multivariate Data Analysis. Prentice Hall International, Inc.: New York; 799. 
Hosking JRM, Wallis JR. 1987. Parameter and quantile estimation for the Generalized Pareto distribution. Technometrics 29(3): 339-349.

Hosking JRM, Wallis JR. 1993. Some statistics useful in regional frequency analysis, Water Resources Research 29: 271-281.

Hosking JRM, Wallis JR. 1997. Regional frequency analysis: an approach based on L-moments. Cambridge University Press, Cambridge, U.K.

Hudson G, Wackernagel H. 1994. Mapping temperature using kriging with external drift: theory and an example from Scotland. International Journal of Climatology 14:77-91.

Knotters M, Brus D, Voshaar J. 1995. A comparison of kriging, co-kriging and kriging combined with regression for spatial interpolation of horizon depth with censored observations. Geoderma 67: 227-246.

Lana X, Burgueño A. 1998. Spatial and temporal characterization of annual extreme droughts in catalonia (northeast Spain). International Journal of Climatology 18: 93-110.

Lana X, Martínez MD, Serra C, Burgueño A. Spatial and temporal variability of the daily rainfall regime in Catalonia (northeastern Spain), 1950-2000. International Journal of Climatology 24: 613-641.

Landwehr JM, Matalas NC, Wallis JR. 1979. Probability weighted moments compared with some traditional techniques in estimating Gumbel parameters and quantiles. Water Resources Research 15: $1055-1064$.

Llasat MC. 1990. Influencia de la orografía y de la inestabilidad convectiva en la distribución espacial de lluvias extremas en Cataluña. Acta Geologica Hispanica, 25: 197-208.

Llasat MC. 2001. An objective classification of rainfall events on the basis of their convective features: Application to rainfall intensity in the northeast of Spain. International Journal of Climatology 21: $1385-1400$

Llasat MC, Rodríguez R. 1992. Extreme rainfall events in Catalonia. The case of 12 November 1988. Natural Hazards, 5: 133-151.

Llasat MC, Puigcerver M. 1997. Total rainfall and convective rainfall in Catalonia, Spain. International Journal of Climatology 17: 1683-1695.

Llasat MD, Rigo T, Barriendos M. 2003. The 'Montserrat-2000' flash-flood event: A comparison with the floods that have occurred in the northeastern Iberian Peninsula since the 14th century. International Journal of Climatology 23: 453-469.

Llasat MC, Barriendos M, Barrera A, Rigo T. 2005. Floods in Catalonia (NE Spain) since the 14th century. Climatological and meteorological aspects from historical documentary sources and old instrumental records. Journal of Hydrology, 313: 32-47.

Madsen H, Rosbjerg D. 1997. The partial duration series method in regional index-flood modeling, Water Resources Research 33: 737-746.

Martín-Vide J. 2004. Spatial distribution of a daily precipitation concentration index in Peninsular Spain. International Journal of Climatology, 24: 959-971.

Martín-Vide J, Fernández D. 2001. El índice NAO y la precipitación mensual en la España peninsular. Investigaciones Geográficas 26: 41-58.

Martín-Vide J, Olcina J. 2001. Climas y tiempos de España, Madrid, Alianza Editorial.

Martin-Vide J, Lopez-Bustins J.A. 2006. The Western Mediterranean Oscillation and rainfall in the Iberian Peninsula. International Journal of Climatology 26: 1455-1475.

Martínez MD, Lana X, Burgueño A, Serra C. 2007. Spatial and temporal daily rainfall regime in

810 Catalonia (NE Spain) derived from tour precipitation indices, yeras 1950-2000. International Journal of Climatology 27: 123-138.

Martinez-Casasnovas JA, Ramos MC. 2006. The cost of soil erosion in vineyard fields in the PenedesAnoia Region (NE Spain). Catena 68: 194-199.

814 Martins ES, Stedinger JR. 2001. Generalized maximum likelihood Pareto-Poisson estimators for partial duration series. Water Resources Research 37 (10): 2551-2557.

816 McBratney A, Mendonça-Santos M, Minasny B. 2003. On digital soil mapping. Geoderma 117: 3-52.

Mitasova H, Mitas L. 1993. Interpolation by regularized Spline with tension. Mathematical Geology 25 : $641-655$. 
Muñoz-Diaz D, Rodrigo FS. 2004. Spatio-temporal patterns of seasonal rainfall in Spain (1912-2000) using cluster and principal component analysis: comparison. Annales Geophysicae 22: 14351448.

322 Nalder IA, Wein RW. 1998. Spatial interpolation of climatic Normals: test of a new method in the Canadian boreal forest. Agricultural and Forest Meteorology, 92: 211-225.

824 Ninyerola M, Pons X, Roure JM. 2000. A methodological approach of climatological modelling of air temperature and precipitation through GIS techniques. International Journal of Climatology 20: 1823-1841.

Ninyerola M, Pons X, Roure JM. 2007. Objective air temperature mapping for the Iberian Peninsula using spatial interpolation and GIS. International Journal of Climatology 27: 1231-1242.

Pastor F, Estrela MJ, Peñarrocha D, Millán M. 2001. Torrencial rains on the Spanish Mediterranean coast: modeling the effects of the sea surface temperature. Journal of Applied Meteorology 40: 1180-1195.

Peñarrocha D, Estrela, MJ, Millán M. 2002. Classification of daily rainfall patterns in a Mediterranean area with extreme intensity levels: the Valencia region. International Journal of Climatology 22: 677-695.

Pons X. 1996. Estimación de la Radiación Solar a partir de modelos digitales de elevaciones. Propuesta metodológica. Proceedings VII Coloquio de Geografía Cuantitativa, Sistemas de Información Geográfica y Teledetección. Vitoria-Gasteiz (Spain). [http://magno.uab.es/atles-climatic/rad pot.pdf].

Pons X. 2006. Manual of miramon. Geographic Information System and Remote Sensing Software. Centre de Recerca Ecol'ogica i Aplicacions Forestals (CREAF): Bellaterra, (http://www.creaf.uab.es/miramon).

Porth LS, Boes DC, Davis RA, Troendle CA, King RM. 2001. Development of a technique to determine adequate sample size using subsampling and return interval estimation. Journal of Hydrology 251: $110-116$.

Prudhome C, Reed DW. 1999. Mapping extreme rainfall in a mountainous region using geostatistical techniques: A case study in Scotland. International Journal of Climatology 19: 1337-1356.

Puigcerver M, Alonso S, Lorente J, Llasat MC, Redaño A, Bargueño A, Vilar E. 1986. Preliminary aspects of rainfall rates in the North East of Spain. Theoretical and Applied Climatology, 37: 97109.

Ramos MC, Martinez-Casasnovas JA. 2006. Trends in precipitation concentration and extremes in the Mediterranean Penedes-Anoia region, NE Spain. Climatic Change 74: 457-474.

Ramis C, Llasat MC, Genovés A, Jansá A. 1997. The october, 1987 floods in Catalonia: synoptic and meso-scale mechanisms. Meteorological Applications 1: 337-350.

Rao AR, Hamed KH. 2000. Flood Frequency Analysis. CRC Press.

Rodó X, Baert E, Comín FA. 1997. Variations in seasonal rainfall in southern Europe during the present century: relationshpis with the North Atlantic Oscillation and the El Niño-Southern oscillation. Climate Dynamics 13: 275-284.

Rodrigo FS, Trigo RM. 2007. Trends in daily rainfall in the Iberian Peninsula from 1951 to 2002. International Journal of Climatology 27: 513-529.

Romero R, Guijarro JA, Ramis C, Alonso S. 1998. 30-year (1964-1993) daily rainfall data base for the Spanish Mediterranean regions: first exploratory study. International Journal of Climatology 18: $541-560$

Romero R, Ramis C, GuijarroJA, Sumner G. 1999a. Daily rainfall affinity areas in Mediterranean Spain. International Journal of Climatology 19: 557-578.

Romero R, Sumner G, Ramis C, Genovés A. 1999b. A classification of the atmospheric circulation patterns producing significant daily rainfall in the Spanish Mediterranean area. International Journal of Climatology 19: 765-785.

Rodríguez-Puebla C, Encinas AH, Nieto S, Garmendia J. 1998. Spatial and temporal patterns of annual precipitation variability over the Iberian Peninsula. International Journal of Climatology 18: 299316. 
Rodriguez-Puebla C, Encinas AH, Saenz J. 2001. Winter precipitation over the Iberian peninsula and its relationship to circulation indices. Hydrology and Earth System Sciences 5: 233-244

Rosbjerg D, Madsen H, Rasmussen PF. 1992. Prediction in partial duration series with generalized Pareto-distributed exceedances. Water Resources Research 28 (11), 3001-3010.

Ruiz, E., (1982): La transición climática del Cantábrico Oriental al valle medio del Ebro. Diputación Foral de Álava. $651 \mathrm{pp}$.

Serrano A, García JA, Mateos VL, Cancillo ML, Garrido J. 1999. Monthly modes of variation of precipitation over the Iberian peninsula. Journal of Climate 12: 2894-2919.

Stedinger JR, Lu LH. 1995. Appraisal of regional and index flood quantile estimators, Stochastic Hydrol. Hydraul. 9: 49-75.

Trigo R, Zezere JL, Rodrigues ML, Trigo IF. 2005. The influence of the North Atlantic Oscillation on rainfall triggering of landslides near Lisbon. Natural Hazards 36: 331-354.

van Montfort MAJ, Witter JV. 1986. The Generalized Pareto distribution applied to rainfall depths. Hydrological Sciences Journal 31 (2), 151-162.

Vicente-Serrano SM, Beguería S. 2003. Estimating extreme dry-spell risk in the middle Ebro valley (northeastern Spain): A comparative analysis of partial duration series with a General Pareto distribution and Annual maxima series with a Gumbel distribution. International Journal of Climatology 23: 1103-1118.

Vicente Serrano SM, Saz MA, Cuadrat JM. 2003. Comparative analysis of interpolation methods in the middle Ebro valley (Spain): application to annual precipitation and temperature. Climate Research 24: 161-180.

392

Vicente-Serrano SM. 2005. Las sequías climáticas en el valle medio del Ebro: Factores atmosféricos, evolución temporal y variabilidad espacial. Consejo de Protección de la Naturaleza de Aragón. $277 \mathrm{pp}$.

Vicente-Serrano SM. 2006. Spatial and temporal analysis of droughts in the Iberian Peninsula (19102000). Hydrological Sciences Journal 51: 83-97

Vicente-Serrano SM, López-Moreno JI. 2006. The influence of atmospheric circulation at different spatial scales on winter drought variability through a semiarid climatic gradient in north east Spain. International Journal of Climatology 26: 1427-1456.

Vicente-Serrano SM, Lanjeri S, López-Moreno JI. 2007. Comparison of different procedures to map reference evapotranspiration using geographical information systems and regression-based techniques. International Journal of Climatology 27: 1103-1118.

Vogel RM, Fennessey NM. 1993. L-moment diagrams should replace product moment diagrams. Water Resources Research 29: 1745-1752.

Wang QJ. 1991. The POT model described by the Generalized Pareto distribution with Poisson arrival rate. Journal of Hydrology 129, 263-280.

Weisse AK, Bois P. 2001. Topographic effects on statistical characteristics of heavy rainfall and mapping in the French Alps. Journal of Applied Meteorology 40 : 720-740.

Willmott CJ. 1981. On the validation of models. Physical Geography 2: 184-194.

910 Willmott CJ. 1982. Some comments on the evaluation of model performance. Bulletin of the American Meteorological Society 63:1309-1313.

912 Willmott CJ, Matsuura K. 2005. Advantages of the mean absolute error (MAE) over the root mean square error (RMSE) in assessing average model performance. Climate Research 30: 79-82.

914 White S, Garcia-Ruiz JM, Marti C, Valero B, Errea MP, Gómez-Villar A. 1997. The 1996 Biescas Campsite disaster in the Central Spanish Pyrenees, and its temporal and spatial context. Hydrological Processes 11: 1797-1812. 
718 Table 1. List of independent geographic and topographic covariates using for regression-based interpolation of the Exponential distribution parameters

\begin{tabular}{ll}
\hline LAT & Latitude $(\mathrm{km})$ \\
LONG & Longitude $(\mathrm{km})$ \\
D_SEA & Distance to the Sea $(\mathrm{km})$ \\
D_MED & Distance to Mediterranean Sea $(\mathrm{km})$ \\
D_ATL & Distance to Atlantic Ocean $(\mathrm{km})$ \\
ELEV & Elevation $(\mathrm{m})$ \\
ELEVx & Average elevation $(\mathrm{m})$ within $x$, where $x$ is a circular window with radii of $2.5,5$, and $25 \mathrm{~km}$ \\
RAD & Annual average incoming solar radiation (MJ $\times$ day) \\
RADx & Annual average incoming solar radiation $(\mathrm{MJ} \times$ day) within $x$, where $x$ is a circular window with \\
SLOPE & $\begin{array}{l}\text { radii of } 2.5,5, \text { and } 25 \mathrm{~km} \\
\text { Slope gradient }(\%)\end{array}$ \\
\hline
\end{tabular}


922 Table 2: Several error statistics used as goodness-of-fit and model validation in this work.

\section{Definitions: \\ $N$ : number of observations, \\ O: observed value, \\ : mean of observed values, \\ $P$ : predicted value,}

MBE

(Mean bias error)

MAE

(Mean absolute error)

$D$

(Agreement index) 
926 Table 3. Goodness of fit of the Exponential distributions, at-site analysis $\left(Q Q W R^{2}\right.$ goodness of fit statistic): a) event duration; b) event magnitude; c) peak intensity.

\begin{tabular}{lllll} 
a) & average & st. dev & $\max$ & $\min$ \\
\hline annual & 0.955 & 0.002 & 0.957 & 0.952 \\
winter & 0.967 & 0.008 & 0.975 & 0.960 \\
spring & 0.872 & 0.008 & 0.880 & 0.864 \\
summer & 0.919 & 0.004 & 0.924 & 0.916 \\
autumn & 0.908 & 0.069 & 0.979 & 0.841 \\
\hline
\end{tabular}

b)

\begin{tabular}{lllll}
\hline annual & 0.965 & 0.010 & 0.974 & 0.954 \\
winter & 0.917 & 0.006 & 0.922 & 0.911 \\
spring & 0.941 & 0.003 & 0.943 & 0.938 \\
summer & 0.932 & 0.040 & 0.970 & 0.891 \\
autumn & 0.854 & 0.135 & 0.984 & 0.713 \\
\hline
\end{tabular}

c)

\begin{tabular}{lllll}
\hline annual & 0.962 & 0.028 & 0.998 & 0.789 \\
winter & 0.916 & 0.057 & 0.995 & 0.673 \\
spring & 0.927 & 0.054 & 0.998 & 0.714 \\
summer & 0.921 & 0.058 & 0.996 & 0.670 \\
autumn & 0.924 & 0.054 & 0.993 & 0.704 \\
\hline
\end{tabular}

928 
930 Table 4. Goodness of fit of the Exponential distribution parameters regression models $\left(R^{2}\right)$, and variables entering in each model: a) peak intensity; b) magnitude; c) duration; d) annual frequency of events ( $\lambda$

932 parameter). The order of the variables indicates their importance in the model.

\begin{tabular}{|c|c|c|}
\hline a) & $\mathrm{R}^{2}$ & Variables \\
\hline Annual $(\alpha)$ & 0.73 & D_SEA, SLOPE10, D_ATL, ELEV10, ELEV, D_MED, SLOPE25, ELEV25, RAD25 \\
\hline Annual $(\xi)$ & 0.70 & SLOPE25, D_SEA, RAD25, ELEV25, ELEV10, LAT, D_MED, LONG \\
\hline Autumn $(\alpha)$ & 0.62 & D_SEA, RAD25, D_ATL, ELEV25, D_MED, SLOPE25, ELEV \\
\hline Autumn $(\xi)$ & 0.73 & D_SEA, RAD25, ELEV25 LAT, SLOPE25, ELEV10, D_MED, D_ATL \\
\hline Winter $(\alpha)$ & 0.64 & D_SEA, SLOPE10, D_ATL, LAT, D_MED, ELEV25, ELEV, SLOPE25, SLOPE5 \\
\hline Winter $(\xi)$ & 0.68 & SLOPE10, D_SEA, RAD25, D_MED, D_ATL, ELEV25, SLOPE25, ELEV \\
\hline Spring $(\alpha)$ & 0.61 & D_SEA, SLOPE10, ELEV25, D_ATL, ELEV, SLOPE5, D_MED, SLOPE25, RAD10 \\
\hline Spring $(\xi)$ & 0.58 & ELEV25, D_SEA, SLOPE25, ELEV5 \\
\hline Summer $(\alpha)$ & 0.22 & D_SEA, SLOPE10, ELEV10 \\
\hline Summer $(\xi)$ & 0.46 & RAD25, LONG, SLOPE10, D_SEA \\
\hline
\end{tabular}

b)

\begin{tabular}{lll}
\hline Annual $(\alpha)$ & 0.65 & D_SEA, SLOPE10, LONG, ELEV25, SLOPE25, D_MED, ELEV, LAT \\
Annual $(\xi)$ & 0.65 & SLOPE25, D_SEA, D_MED, SLOPE10, ELEV25, ELEV5, RAD25, LAT, LONG, D_ATL \\
Autumn $(\alpha)$ & 0.63 & D_SEA, SLOPE10, LAT, ELEV25, D_MED, D_ATL, SLOPE25, ELEV \\
Autumn $(\xi)$ & 0.63 & SLOPE25, D_SEA, SLOPE10, D_MED, ELEV25, RAD25, LAT, ELEV5 \\
Winter $(\alpha)$ & 0.56 & SLOPE10, D_SEA, D_ATL, D_MED, ELEV25, SLOPE25, ELEV, SLOPE5 \\
Winter $(\xi)$ & 0.64 & SLOPE10, D_SEA, D_MED, ELEV25, RAD25, D_ATL, SLOPE25, ELEV5, SLOPE5 \\
Spring $(\alpha)$ & 0.58 & D_SEA, RAD25, ELEV25, D_MED, SLOPE25, ELEV5 \\
Spring $(\xi)$ & 0.58 & SLOPE10, D_SEA, ELEV25, D_MED, SLOPE25, ELEV5, RAD5, SLOPE5 \\
Summer $(\alpha)$ & 0.39 & SLOPE10, D_SEA, D_ATL, RAD5, ELEV10 \\
Summer $(\xi)$ & 0.52 & LAT, SLOPE10, D_SEA, RAD25 \\
\hline
\end{tabular}

c)

$\begin{array}{lll}\text { Annual }(\alpha) & 0.67 & \text { D_MED, SLOPE10, D_SEA, D_ATL } \\ \text { Annual }(\xi) & 0.70 & \text { D_MED, D_SEA, LONG, SLOPE10, SLOPE5, RAD10, RADIAC25 } \\ \text { Autumn }(\alpha) & 0.56 & \text { D_MED, D_SEA, SLOPE10, D_ATL, LONG, LAT } \\ \text { Autumn }(\xi) & 0.66 & \text { D_SEA, SLOPE10, D_MED, RAD10, SLOPE5, LONG } \\ \text { Winter }(\alpha) & 0.53 & \text { D_MED, D_SEA, SLOPE10, LAT } \\ \text { Winter }(\xi) & 0.62 & \text { D_ATL, SLOPE10, D_SEA, D_MED, RAD25, SLOPE25 } \\ \text { Spring }(\alpha) & 0.65 & \text { D_MED, LONG, SLOPE10, D_SEA, RAD10, LAT, D_ATL } \\ \text { Spring }(\xi) & 0.68 & \text { SLOPE10, D_MED, D_SEA, RAD10, LONG, SLOPE25, RAD25 } \\ \text { Summer }(\alpha) & 0.34 & \text { D_MED, SLOPE, D_ATL, RAD5 } \\ \text { Summer }(\xi) & 0.66 & \text { LAT, D_SEA, D_MED, SLOPE10, LONG, D_ATL, RAD25 }\end{array}$

d)

\begin{tabular}{lll}
\hline$\lambda$ (annual) & 0.58 & LAT, RAD25, SLOPE25, D_SEA, ELEV25 \\
$\lambda$ (autumn) & 0.49 & LAT, RAD25, SLOPE25, D_SEA, ELEV25 \\
$\lambda$ (winter) & 0.65 & D_MED, LAT, RAD25, SLOPE25, ELEV \\
$\lambda$ (spring) & 0.50 & LAT, ELEV, D_SEA, RAD25, SLOPE25 \\
$\lambda$ (summer) & 0.58 & LAT, SLOPE25, RAD25, D_ATL \\
\hline
\end{tabular}


936 Table 5. Error/accuracy statistics for annual and seasonal quantile estimates for a 30 years return period:

a) peak intensity; b) magnitude; and d) duration.

\begin{tabular}{lrrrr} 
& Average & MAE & MBE & $D$ \\
a) & & & & \\
\hline annual & 99.84 & 8.60 & 1.28 & 0.96 \\
\hline autumn & 87.01 & 11.00 & 1.27 & 0.95 \\
winter & 68.73 & 8.94 & 1.26 & 0.95 \\
spring & 64.70 & 7.84 & -1.46 & 0.91 \\
summer & 68.58 & 7.19 & -0.43 & 0.88 \\
\hline
\end{tabular}

b)

\begin{tabular}{lrrrr}
\hline annual & 228.41 & 43.74 & -29.78 & 0.85 \\
\hline autumn & 172.03 & 25.26 & -4.12 & 0.94 \\
winter & 159.05 & 25.51 & -0.60 & 0.93 \\
spring & 144.82 & 23.54 & -12.19 & 0.90 \\
summer & 92.79 & 20.44 & 11.85 & 0.70 \\
\hline
\end{tabular}

c)

\begin{tabular}{lrrrr}
\hline annual & 12.27 & 1.17 & 0.26 & 0.96 \\
\hline autumn & 8.92 & 1.25 & 0.23 & 0.92 \\
winter & 9.84 & 1.16 & 0.28 & 0.96 \\
spring & 10.10 & 1.31 & 0.08 & 0.93 \\
summer & 7.37 & 1.32 & -0.14 & 0.70 \\
\hline
\end{tabular}

938 


\section{Figure captions}

Figure 1. Spatial location and relief (elevation in $\mathrm{m}$ a.s.1.) of the study area. Daily precipitation series used

942 for modelling and validation are shown

Figure 2. L-moment plots: comparison between theoretical (lines) and empirical (dots) L-skewness (x

944 acis) and L-kurtosis (y axis). Several theoretical distributions are shown: Generalized Pareto (continuous line), Exponential (intersection between the vertical and horizontal lines), Lognormal (dashed line) and

946 Pearson III (dotted line).

Figure 3. Spatial distribution of the Exponential distribution parameters $\hat{\alpha}(x)$ and $\xi(x)$ corresponding to

э48 annual series: 1) peak intensity $\hat{\alpha}(x) ; 2$ ) peak intensity $\xi(x) ; 3)$ magnitude $\hat{\alpha}(x) ; 4)$ magnitude $\xi(x) ; 5)$ duration $\hat{\alpha}(x) ; 6)$ duration $\xi(x)$.

$950 \quad$ Figure 4. Comparison between predicted (y axis) and observed (x axis) annual values of $\hat{\lambda}(x)$ of peak intensity, magnitude and duration for the validation set (10\% of the observatories), line of perfect fit

952 (continuous) and regression line (dashed).

Figure 5. Spatial distribution of $\hat{\alpha}(x)$ corresponding to seasonal series of peak intensity: 1) winter; 2)

954 spring; 3) summer; 4) autumn.

Figure 6. Annual quantiles maps corresponding to a return period of 30 years: 1) peak intensity (mm day

$956 \quad$ 1); 2) magnitude (mm); and 3) duration (days).

Figure 7. Comparison between the quantile estimates of peak intensity, magnitude and duration for a

958 return period of 30 years using spatially modelled (y axis) and at-site (x axis) Exponential distribution parameter estimates, line of perfect fit (continuous) and regression line (dashed).

960 Figure 8 . Seasonal quantile maps of peak intensity $\left(\mathrm{mm}^{-1} \mathrm{day}^{-1}\right)$ corresponding to a return period of 30 years: 1) winter; 2) spring; 3) summer; and 4) autumn.

962 Figure 9. Seasonal quantile maps of rainfall magnitude $(\mathrm{mm})$ corresponding to a return period of 30 years: 1) winter; 2) spring; 3) summer; and 4) autumn.

964 Figure 10. Seasonal quantile maps of rainfall event duration (days) corresponding to a return period of 30 years: 1) winter; 2) spring; 3) summer; and 4) autumn. 
966 Figure 11. Regionalization of the study area as a function of the season in which the maximum quantile estimate is recorded: 1) peak intensity; 2) magnitude; and 3) duration. 


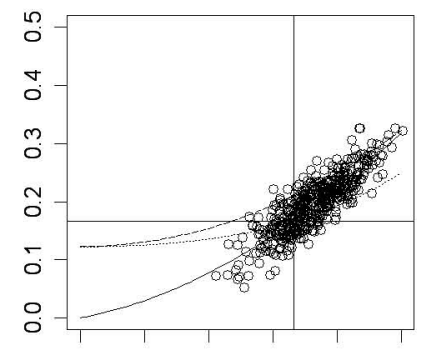

$\begin{array}{llllll}0.0 & 0.1 & 0.2 & 0.3 & 0.4 & 0.5\end{array}$

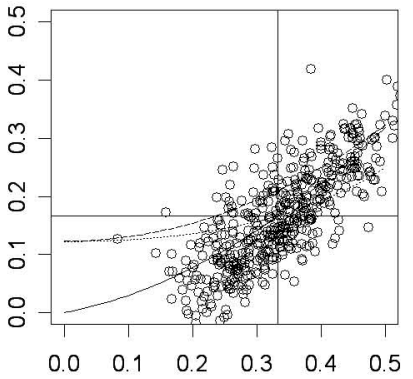

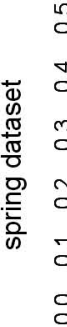

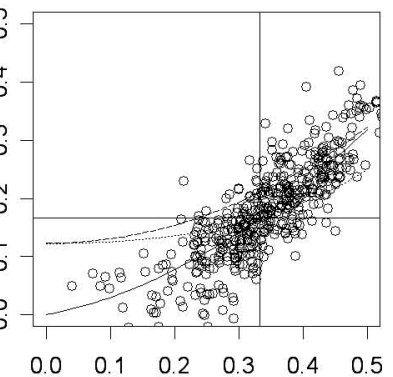

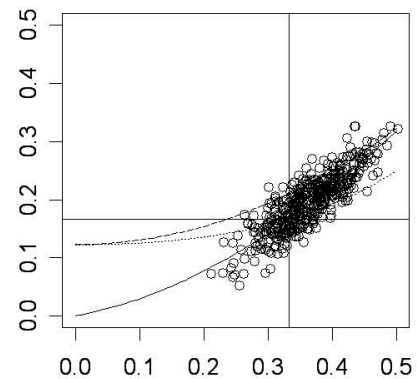
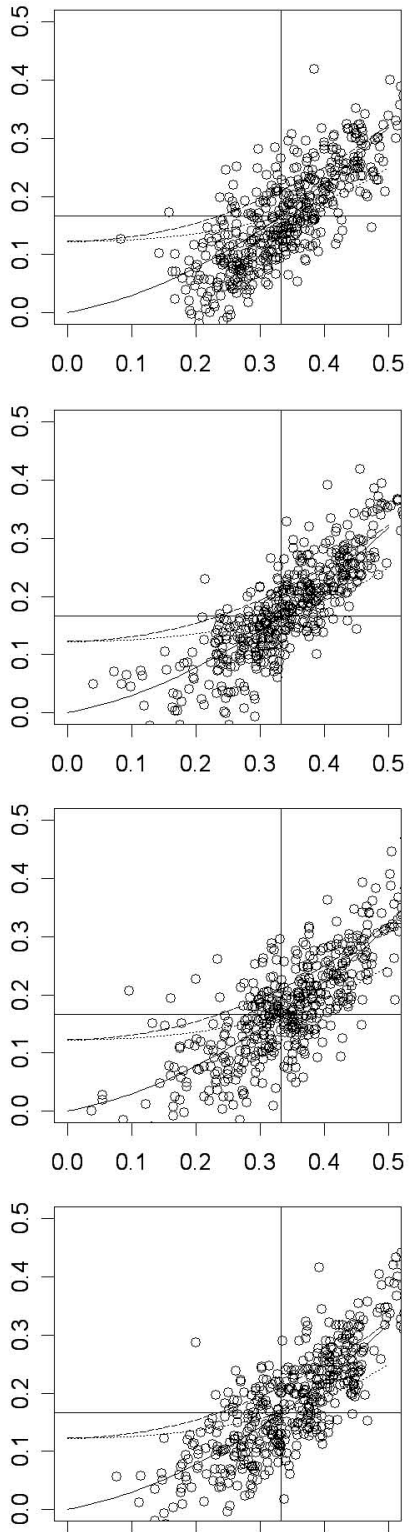
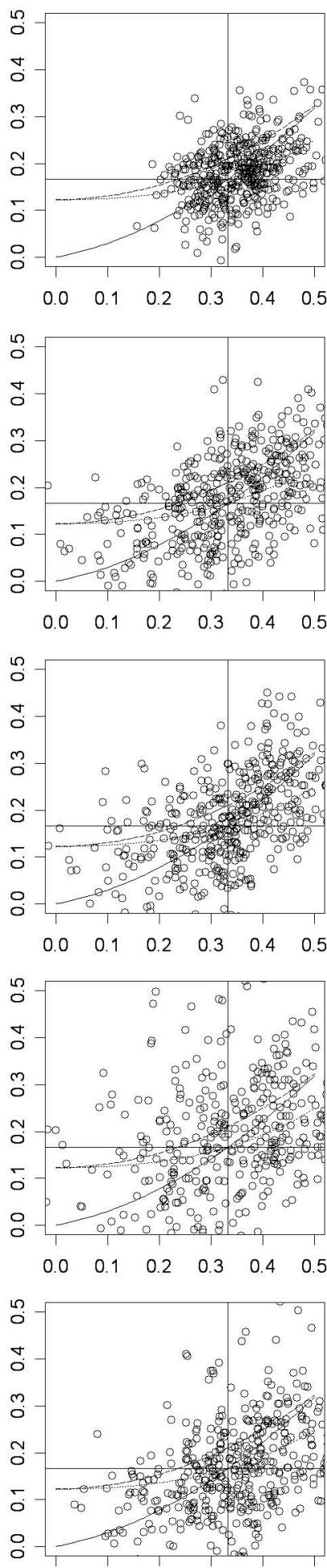


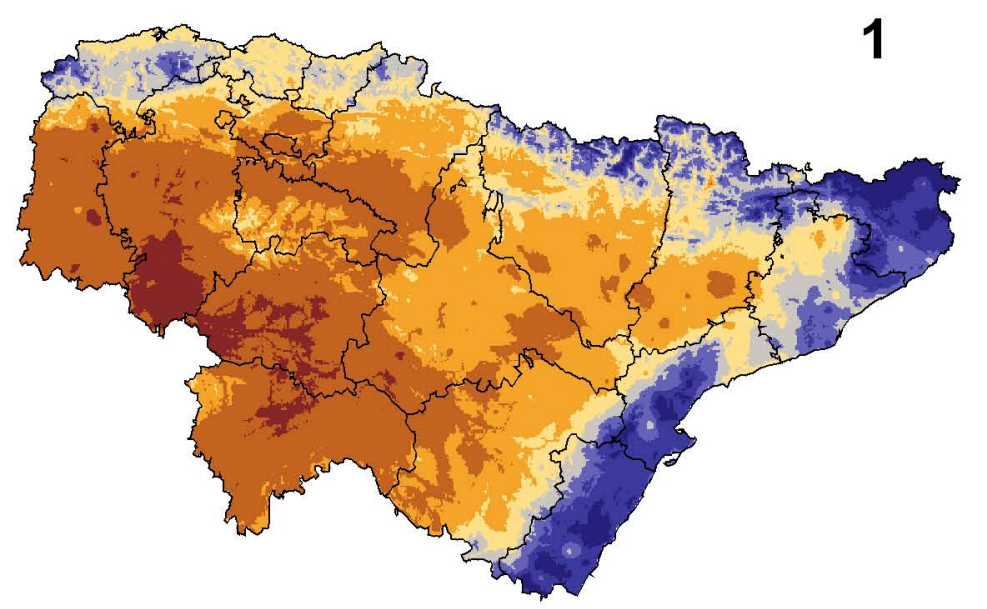

$\begin{array}{lllllll}<8 & 11 & 14 & 17 & 20 & 23 & >26\end{array}$

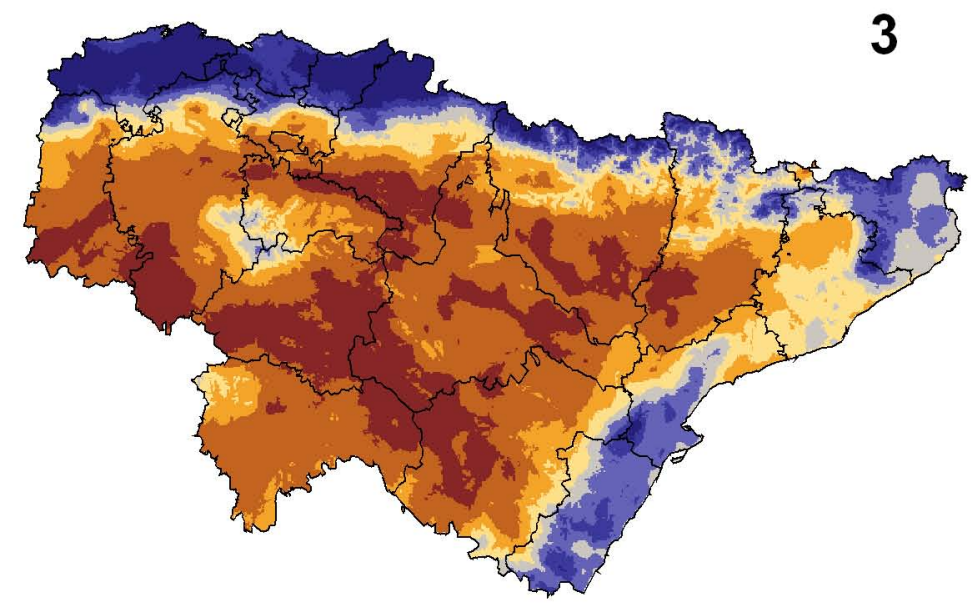

$\begin{array}{lllllll}< & 24 & 30 & 36 & 42 & 48 & >54\end{array}$

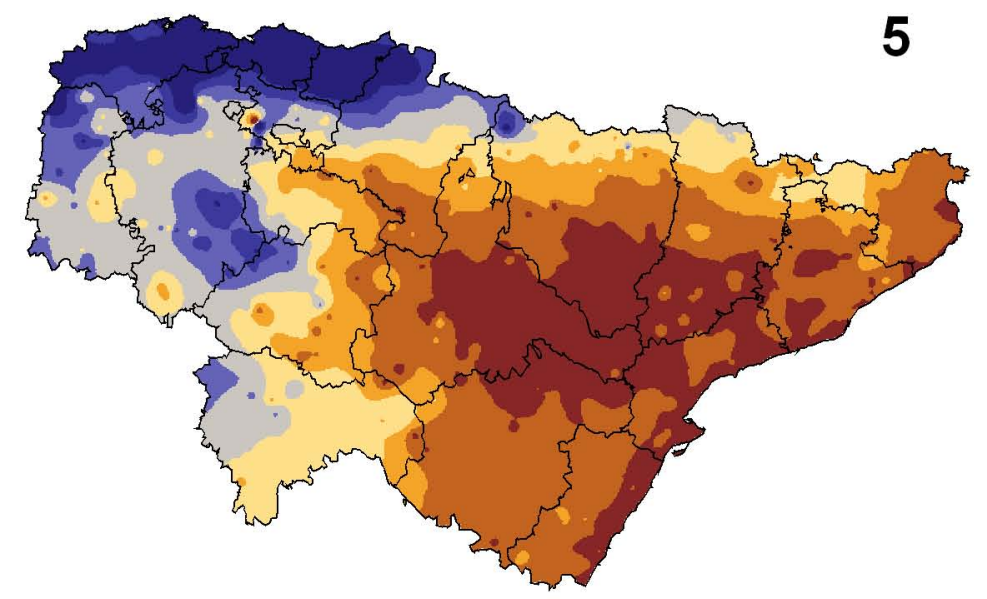
$<1.2$
1.8
2.4
$>3.0$

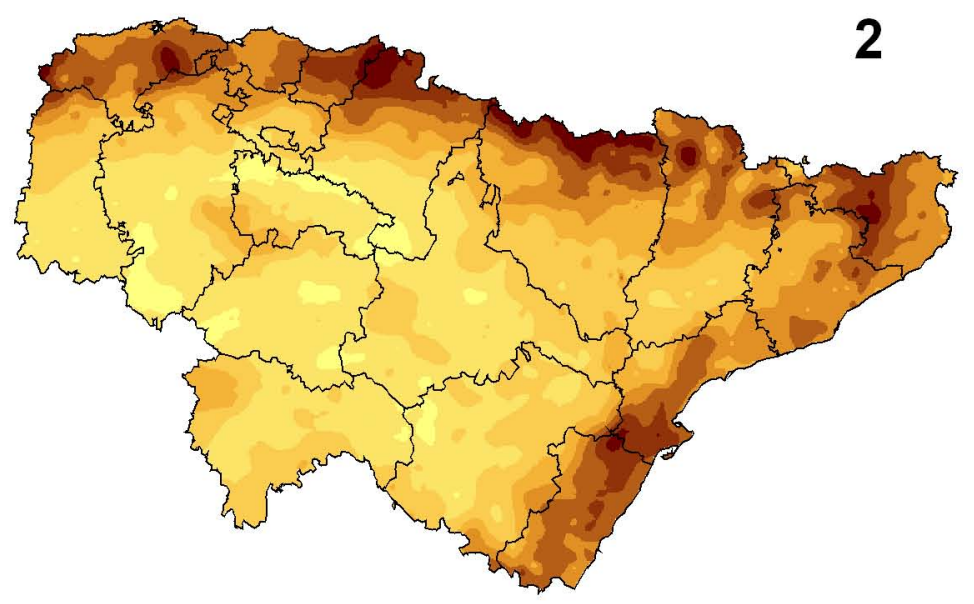

$\begin{array}{lllllll}<18 & 22 & 26 & 30 & 34 & 38 & >42\end{array}$

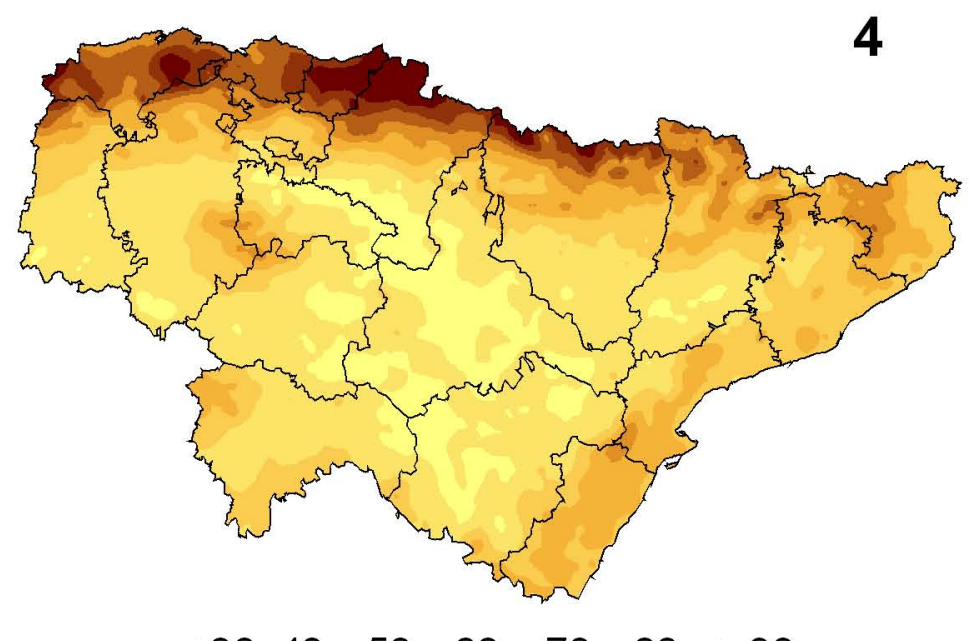

$$
<30 \quad 40 \quad 50 \quad 60 \quad 70 \quad 80 \quad>90
$$

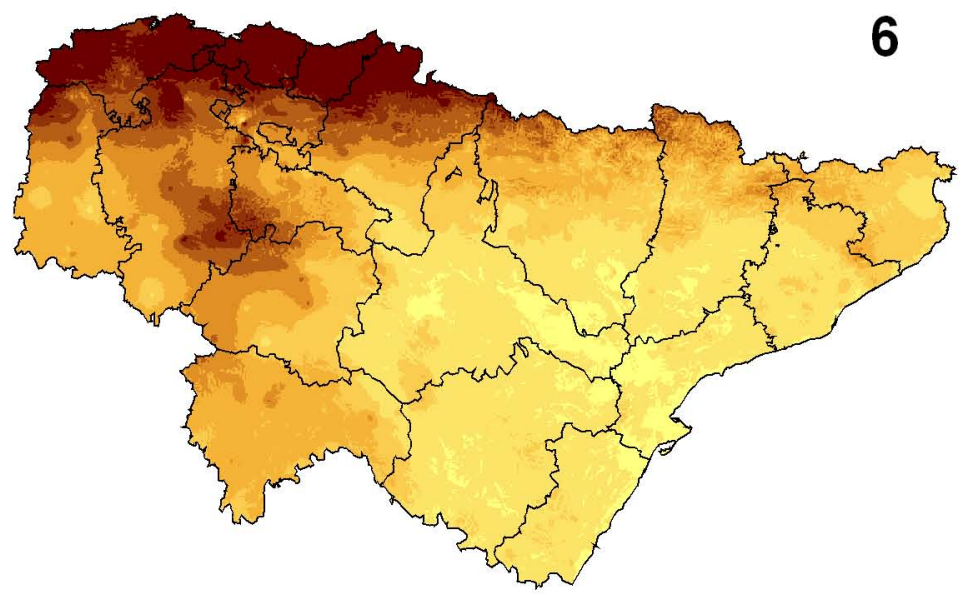

$<3.0 \quad 4.0$

$4.0>5.0$ 
peak intensity ( $\mathrm{mm} /$ day)
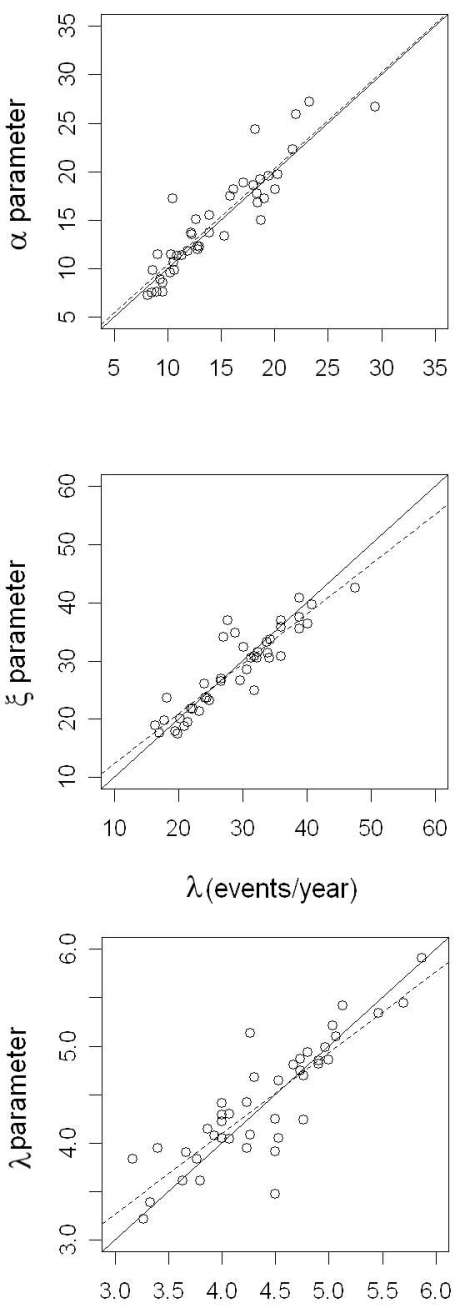
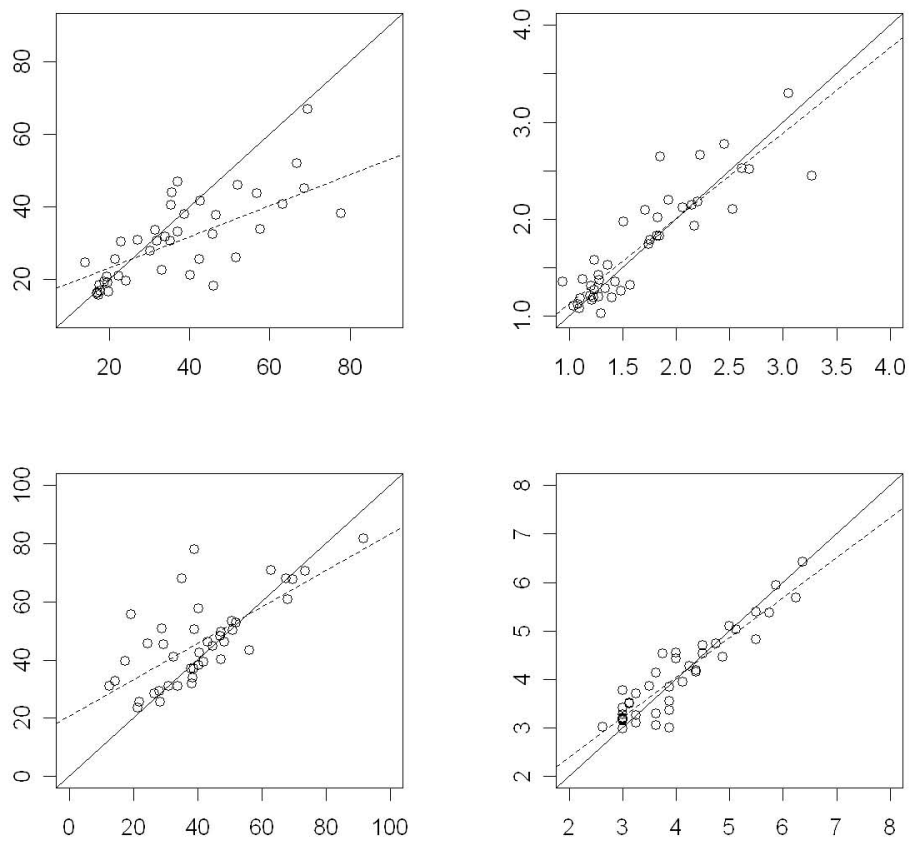

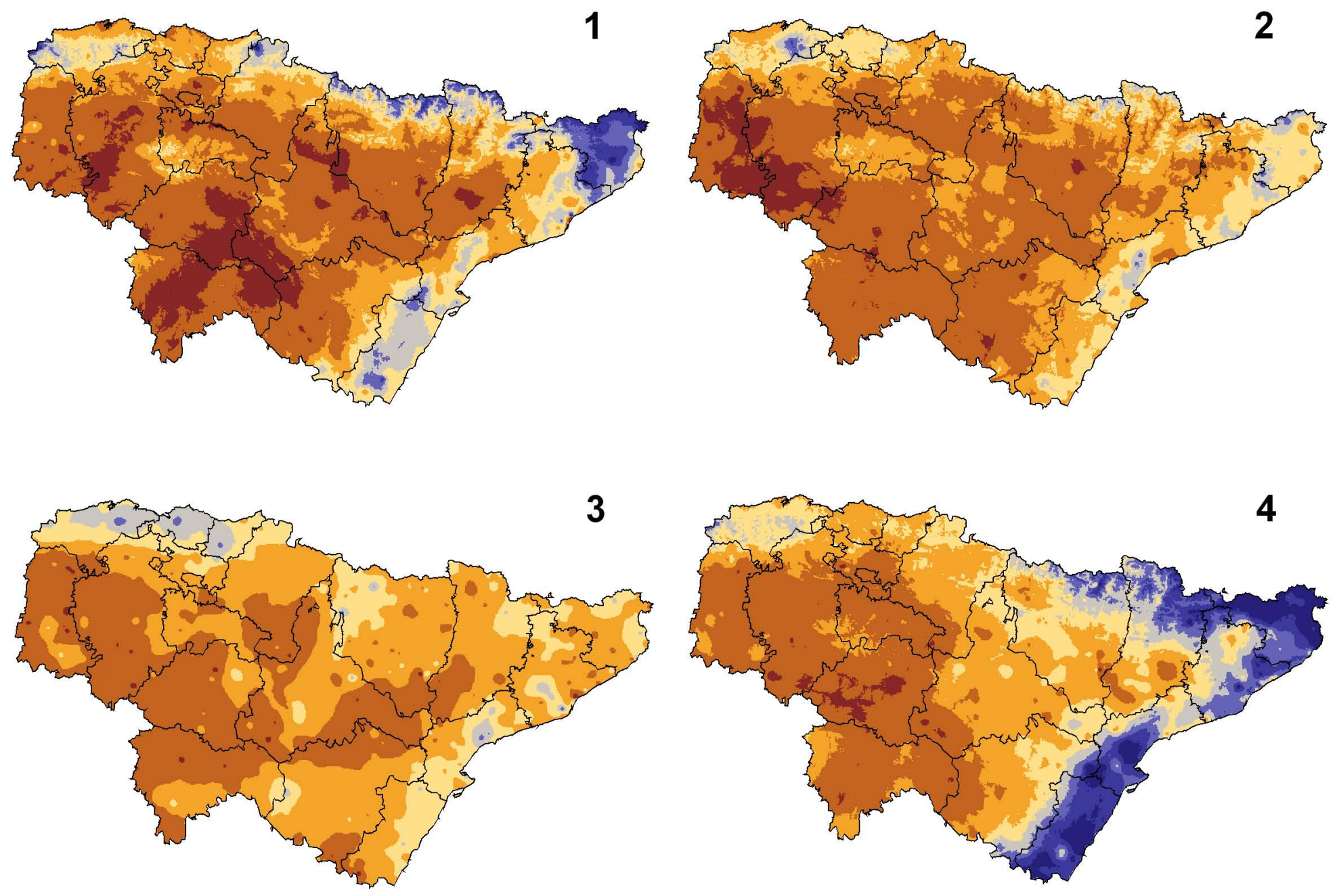

\section{$\begin{array}{lllllll}< & 5 & 7 & 9 & 11 & 13 & >\end{array}$}

$\begin{array}{llll}0 & 50 & 100 \quad 200 \quad 300\end{array}$

400

$\Lambda$ 

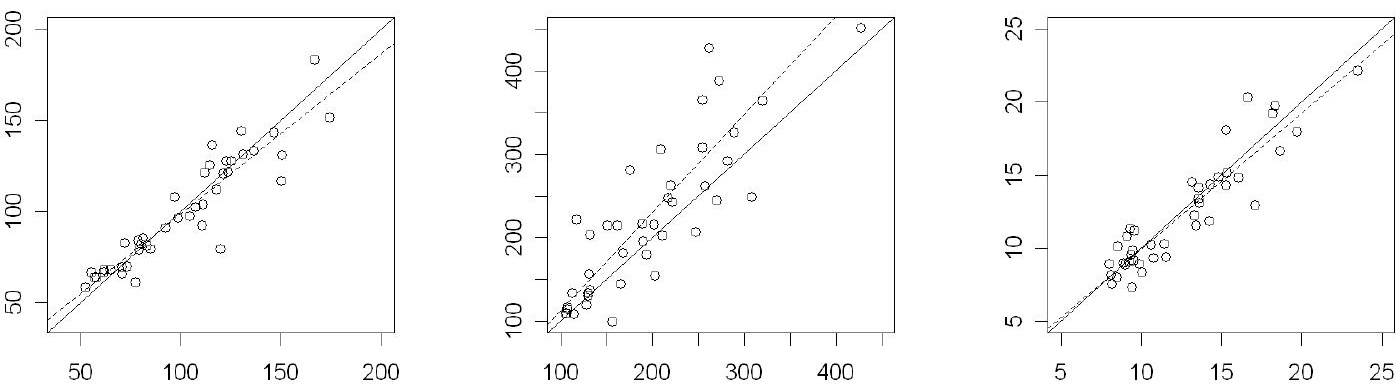

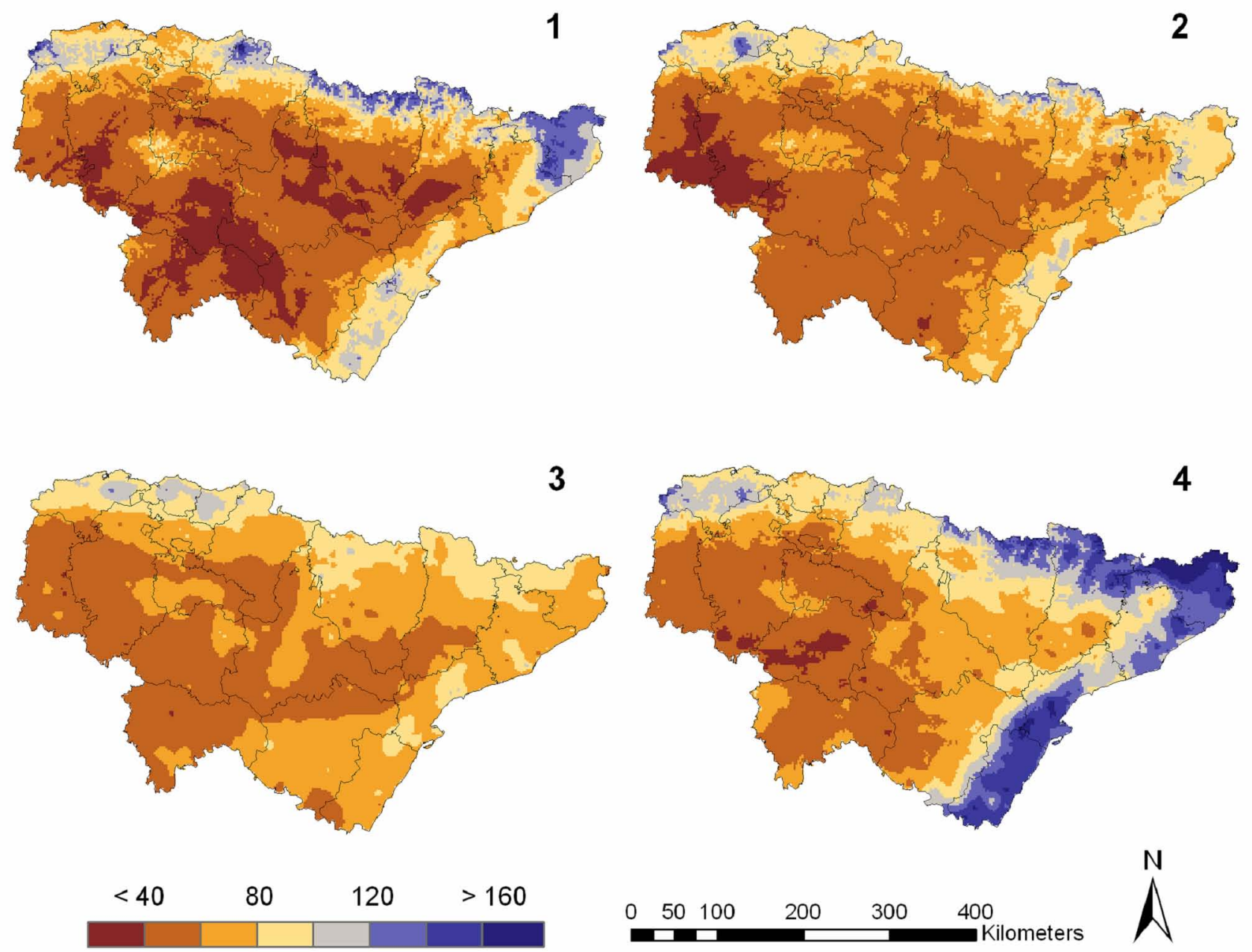

$0 \quad 50 \quad 100$ 

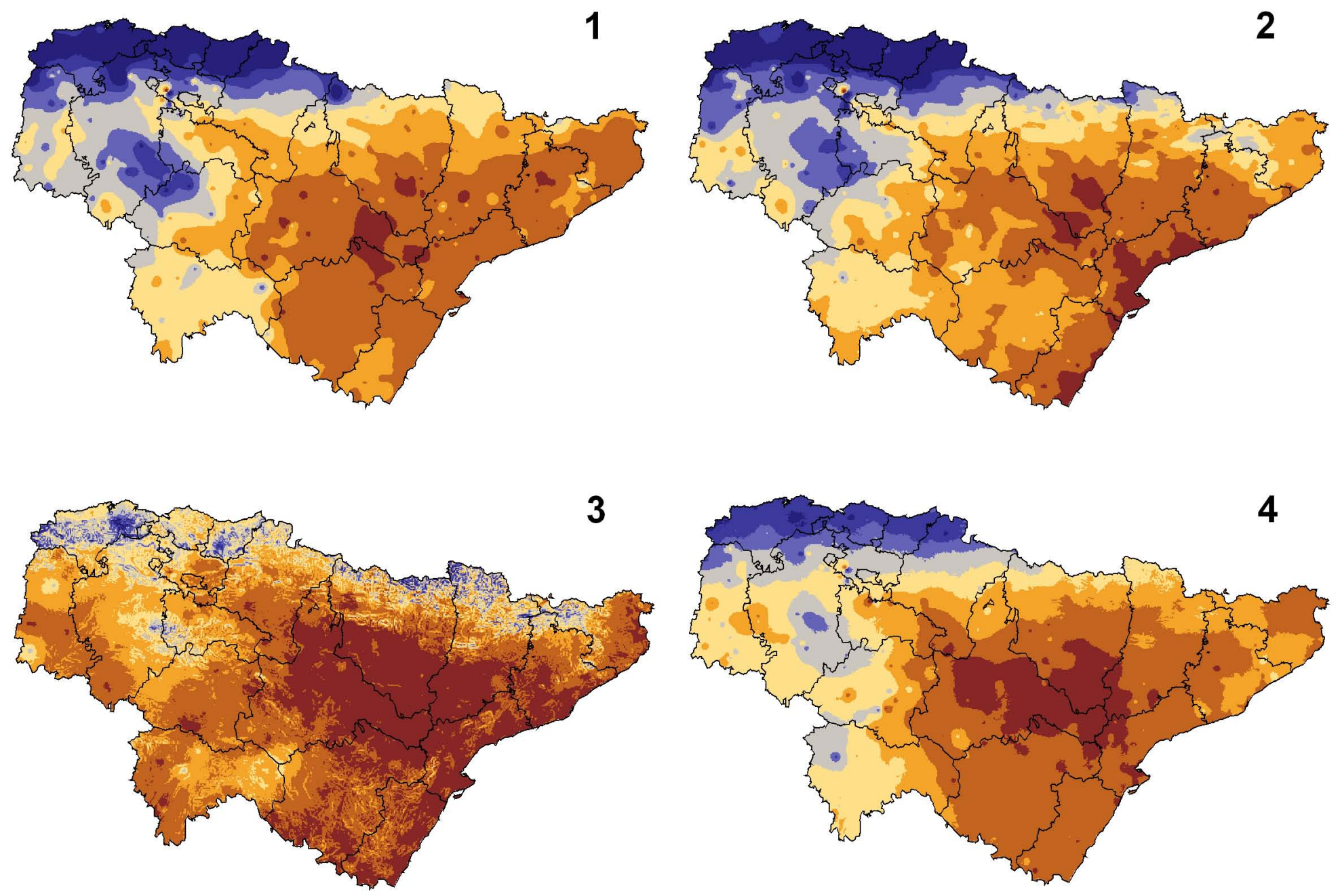

\begin{tabular}{ll|l|l|l}
$<6$ & \multicolumn{1}{l|}{10} & 14 & $>18$
\end{tabular}

$0 \quad 50100$ 

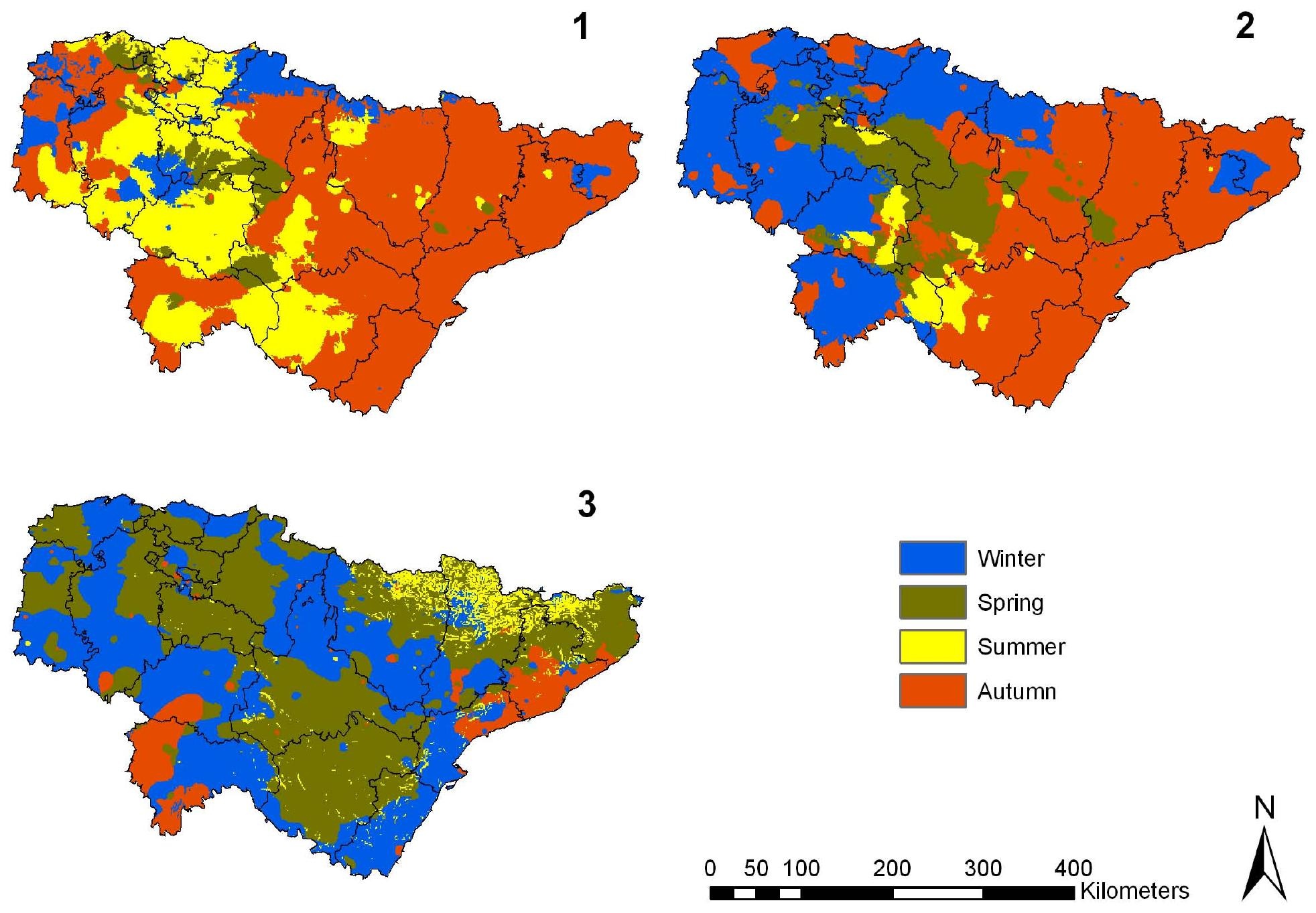